Variability in Historical Fire Patterns of a Moist Mixed-Conifer Forest in the Northern Blue Mountains of Oregon

\title{
by
}

\section{Laura Marie Platt}

A thesis submitted in partial fulfillment of the requirements for the degree of

\author{
Master of Science \\ in \\ Geography
}

Thesis Committee:

Andrés Holz, Chair

Sarah Eppley

Melissa Lucash

Cameron Naficy

Portland State University

2020 


\begin{abstract}
High variability in historical fire patterns characteristic to mixed-severity fire regimes is expected to have contributed to a structurally heterogeneous landscape throughout much of the forested ecosystems of the western United States. After more than a hundred years of fire exclusion in the region, many forests have shifted to a more homogeneous structure, which raises concern regarding these forests' ability to sustain expected increases in fire activity with a warming climate. The shift is not uniform across the west, however, and differences in historical disturbance patterns and changes due to land management are not well characterized in forests across a wide range of environmental settings. While there is broad agreement on the high (low) impact of fire exclusion on the structure and composition of low (high) elevation, dry (wet) forests in the west, much less is known about its effect in mid elevation, moist mixed-conifer forests.

In order to provide reference conditions of wildfire patterns, this study reconstructs the variability in historical fire occurrence and severity and tree establishment in a moist mixed-conifer forest in northeastern Oregon's Blue Mountains. We used a novel multi-proxy approach, combining remote sensing, dendroecology, and mathematical models to comprehensively sample and reconstruct multi-century fire frequency and severity, and forest structural patterns. Based on over 550 tree-core and 100 fire-scar samples collected at 38
\end{abstract}


plots, we quantified historical fire severity and assessed the spatial heterogeneity of disturbance and establishment patterns across 9,300 ha in two subwatersheds. We identified high variability in historical fire patterns over fine scales between forest stands. Despite speculation that moist mixed-conifer forests experienced primarily infrequent and severe fires, relatively frequent fire (median intervals ranging from 14-42 years) of all severities (low, medium and high) at fine scales was common throughout the study area, with an abrupt decrease in fire activity after 1900. Concurrent post-fire establishment pulses of both shade-intolerant and shade-tolerant species were common, suggesting an initial floristics vegetation succession model. The results of this study highlight the complexity of the mixed-severity fire regime, long-term challenges and untested assumptions of post-fire responses of shade-tolerant species, as well as assumed infrequent fire activity in moist mixed-conifer forests, and thus can help inform discussions around appropriate restoration of fire-excluded, moist mixed-conifer forests of the northern Blue Mountains Ecoregion. 


\section{Acknowledgements}

Funding for this research was provided by the Oregon Department of Forestry, The Nature Conservancy, and the Joint Fire Science Program.

Access to conduct fieldwork within our study area was graciously provided by the Umatilla National Forest (USFS). We also acknowledge that this is the ancestral homeland of the Cayuse, Umatilla, Walla Walla, and Nez Perce people.

This work wouldn't have been possible without help from our dedicated field and lab assistants. Thank you, Katya Davidson, Jennifer Litteral, Josefa Ovalle, Joseph Riggs, Desiree Monarrez, Sebastian Singleton, Maddie Collins, Alex Fager, Jeff Smith, Sebastian Busby, Anthony Holmes, Kayla Johnston, Ian Mott, and Devin Wilde for the countless hours, blood, sweat, and tears that you've dedicated to collecting and processing these tree ring samples.

A big thank you to my advisor, Andrés Holz, for providing the opportunity to conduct this exciting research project and for providing helpful thoughts, feedback, and support. A big thank you to Cameron Naficy, for all the training, guidance, and expert insight that has been instrumental to this project. A big thank you to Kerry Kemp, for her help to source project funding, provide crucial local connections, and for the ample and appreciated support. An additional thanks to my thesis committee members, Melissa Lucash and Sarah Eppley, for taking time out of their busy schedules to provide feedback and assess the quality of this work. 
A final thanks to my labmates and friends at the PSU Outdoor Program for the never-ending support and encouragement, and to my partner, Geoff, for his nonexpert feedback, expert graphics guidance, love, and support. 


\section{Table of Contents}

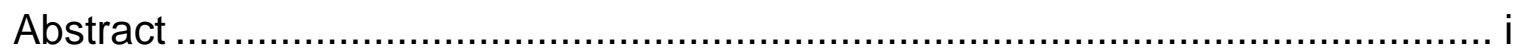

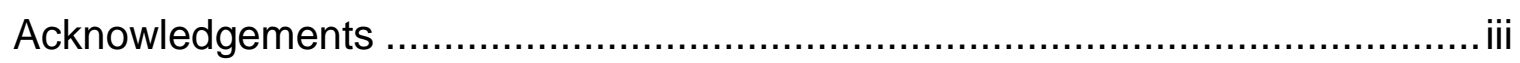

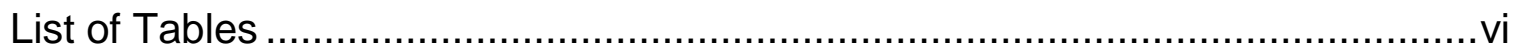

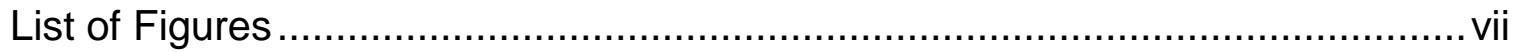

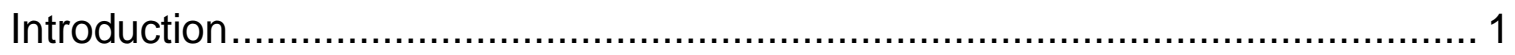

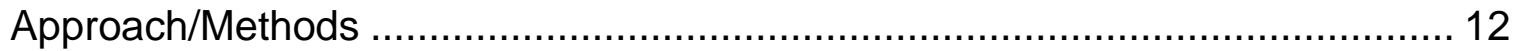

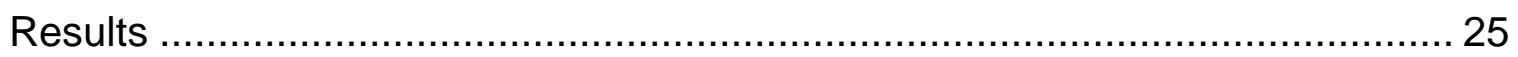

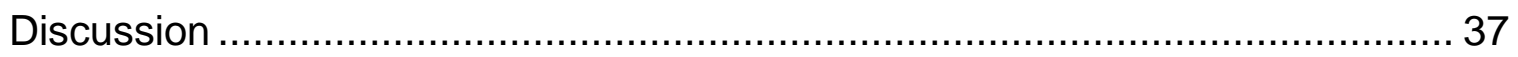

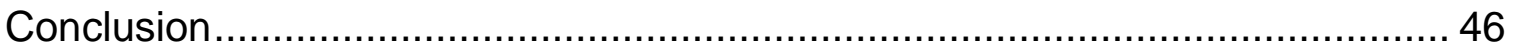

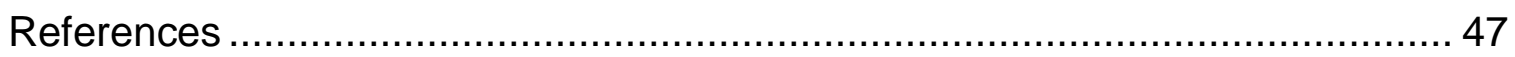

Appendix A Reconstructing fire history from tree ring evidence ....................... 58

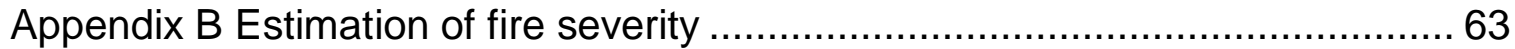




\section{List of Tables}

Table 1: Data collected in this study ...........................................

Table 2: Structural types along a successional gradient and respective sampling

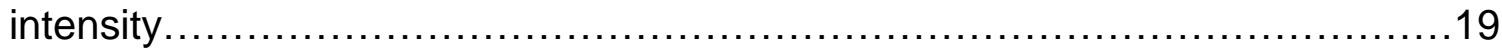

Table 3: Summary and stratification of sampling effort by forest structure in the two sampled subwatersheds, Little Lookingglass Creek and Upper Lookingglass

Creek. 


\section{List of Figures}

Figure 1: Drivers of fire activity over spatial and temporal scales (adapted from Moritz et al. 2005)

Figure 2: Bailey Sections and Subsections in Oregon and Washington, USA with forest vegetation types that exhibit mixed severity fire regimes....

Figure 3: Continuum of forest types found along an elevational gradient on the east side of the Cascade Range in the northwestern US and the relationship of forest type to general fire regimes (from Stine et al. 2014) .......................

Figure 4: Location of study area and two sampled subwatersheds.

Figure 5: Photos depicting the dissected landscape characteristic of the northern Blue Mountains.

Figure 6: Topographic distribution of sampled plots

Figure 7: Sampled patches in the Lookingglass Creek subwatersheds stratified by forest stand structure and dominant overstory species composition

Figure 8: Distribution of distances between sampled fire scar cross-sections and nearest age structure plot. .24

Figure 9: Map of sampled patches with age structure plots and fire scars across the Lookingglass Creek subwatersheds.

Figure 10: Violin boxplot of establishment dates across all patches, establishment demography and fire events for each of the 13 sampled patches, and decadal z-scores of Palmer Drought Severity Index.

Figure 11: Chronologies of fire scars from individual fire scar samples for the Upper and Little Lookingglass Creek subwatersheds

Figure 12: Subwatershed scale fire demography chart for the Lookingglass Creek subwatersheds

Figure 13: Calculated fire intervals for sampled patches shown along a moisture gradient 33

Figure 14: Fire history and age structure of all sampled patches .34 
Figure 15: Establishment demography in patches grouped by forest structure

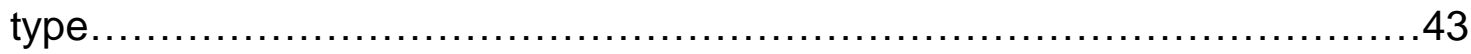




\section{Introduction}

Over recent decades in the western United States, there has been an increase in the frequency of large wildfires due to a lengthening of the fire season with a changing climate (Westerling 2006). This trend, at least in part, is attributable to anthropogenic climate change that continues to lead to increased fuel aridity (Abatzoglou and Williams 2016) and earlier spring snowmelt (Westerling 2006). There is concern that today's forests, many of which have experienced substantial changes over the past century due to Euro-American land use (e.g. grazing, logging, burning, and/or fire suppression; Hessburg et al. 2000), will not be resilient to the anticipated trend in wildfire patterns (Davis et al. 2018). However, local context is important, and it is not fully understood whether and to what degree the effects of past and ongoing climate and land use changes are uniform across all forest ecosystems in the west. Forests that historically experienced mixed-severity fire regimes are thought to have been the most common type in the northwestern US (Perry et al. 2011), but due to the difficulty in studying and classifying historical fire patterns in these forests (Tepley and Veblen 2015; Naficy 2016) they remain the least understood (Schoennagel et al. 2004). Additionally, mid-elevation moist mixed-conifer (MMC) forests, some of which are expected to have experienced mixed-severity fire regimes, are understudied in comparison to the relatively lower elevation, dry pine forests and the higher elevation wet forests (Stine et al. 2014). Thus, a baseline understanding of fire regimes and ecological dynamics is needed in these 
forests, and can inform our understanding of the consequences of past and future stand structural changes under current and projected climate and management scenarios. This information will aid managers to make informed decisions regarding if and where restoration is appropriate.

\section{Drivers of fire activity}

Fire has played an integral role in forest dynamics across the world (Bowman et al. 2009), including throughout the northwestern US (Agee 1993). Over millennia, both human and lightning-ignited fires have sculpted landscapes at various spatial and temporal scales in this region (Agee 1996; Walsh et al. 2015). The most prevalent form of disturbance across the Northwest, prior to Euro-American settlement, was fire (Hessburg and Agee 2003). This history of fire, varying over space and time, is largely a function of climate and its interaction with the landscape.

There are many important factors that determine wildfire patterns at various scales in space and time (Figure 1). At a fundamental level, fire requires fuel, a certain level of fuel aridity, and a source of ignition (Pyne et al. 1996). Across spatiotemporal scales, top-down and bottom up drivers control fire. At coarse scales, fire activity or a fire regime (i.e. wildfire patterns typical to, and their role in, a forest ecosystem; Agee 1993) are driven by top-down controls that include climate (both long-term normal and short-term fluctuations), and ignition patterns, whereas bottom up effects are mediated by vegetation. Fire regimes typically characterize fire activity at a regional scale (i.e. hundreds of $\mathrm{km}^{2}$; Littell 
et al. 2009). At fine scales bottom-up controls, including fuel amount and topography, interact with top-down weather to shape patterns of individual fire events (i.e. km²; Skinner and Taylor 2006).

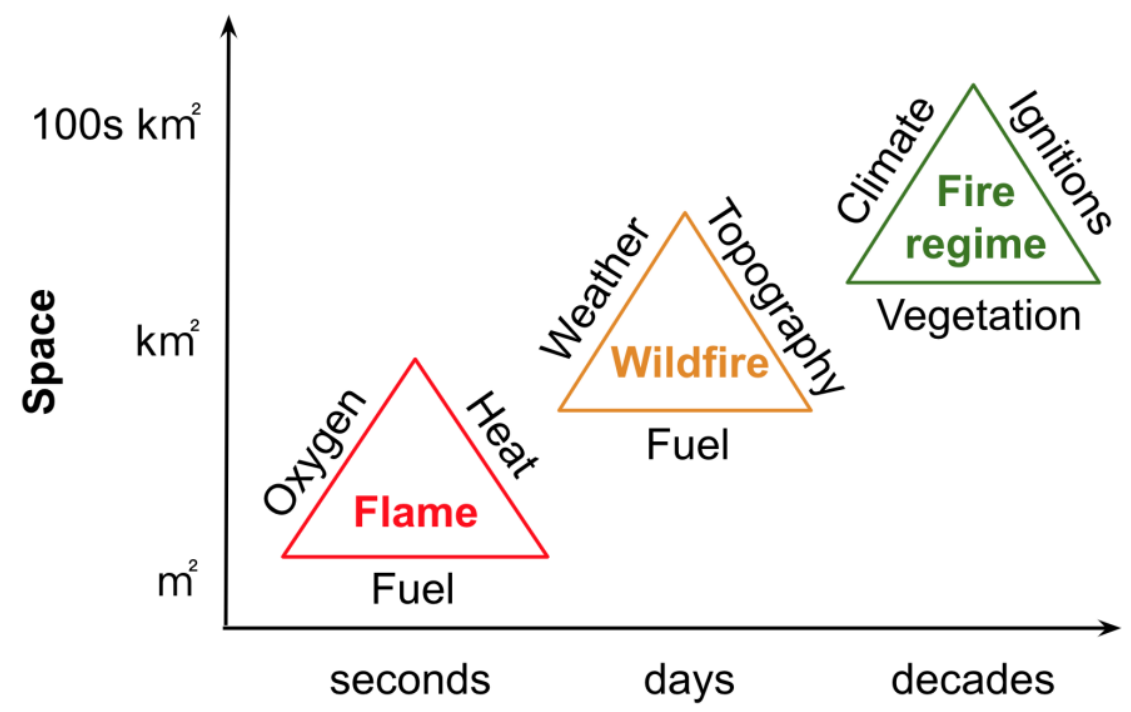

Time

Figure 1. Drivers of fire activity over spatial and temporal scales (adapted from Moritz et al. 2005).

As a concept, fire regimes are central to understanding the character, effect, and variability of these disturbance patterns within and across regions (Schoennagel et al. 2004). Some key attributes of a fire regime include the frequency, severity (i.e. proportion of biomass or density of fire-killed trees), and spatial extent of fires. Most forest ecosystems will experience varying levels of fire severity in the short term or even at the individual fire-event scale, where typically some areas are burned at low, others at mid, and others at high severity. However, it is the dominant drivers and relative frequency over coarser 
spatiotemporal scales at which these ecosystems experience low, moderate, or high severity fire which varies amongst fire regimes (Agee 1993).

An example of a characteristic low-severity fire regime is that of the dry ponderosa pine forests of the western US (Swetnam and Baisan 1996) found at low elevation and/or in dry settings, where a high proportion of fires burn frequently (i.e. every < ca. 25 yrs.), and at low severity. There is typically insufficient fuel loading for these fires to reach tree canopies, where fire is generally more lethal, thus leaving a relatively large proportion of surviving trees on the landscape. These ecosystems are typically referred to as fuel-limited ecosystems, since fire activity is limited by the abundance of fuel (Krawchuk and Moritz 2011). Years of increased fire activity in these dry systems typically occur following pulses of rainfall that enhance fine-fuel buildup that connect typically patchy vegetation (e.g. Moritz et al. 2012). On the opposite end of the spectrum, cool and/or wet forests tend to experience very infrequent (from ca. 200-to up to ca. $1,000+$ yrs.), high severity fires (e.g. Johnson et al. 2001; Gavin et al. 2003; Sibold et al. 2006; Halofsky et al. 2018). These fires are also referred to as stand-replacing fires, and leave few surviving trees. Forest ecosystems where these stand replacing fires typically occur are referred to as climate-limited systems, where the high productivity of the forest provides plenty of fuel for fire, but the limiting factor in fire ignition and spread is largely fuel moisture (Krawchuk and Moritz 2011). 


\section{Mixed-severity fire regimes and methodological challenges}

A majority of the forested area in the northwestern US experiences neither a dominance in high or low severity fire over space or time and have been categorized as mixed-severity fire regimes (Figure 2). Drivers of fire activity in these forests is a complex and variable interaction of climate (top-down) and fuel (bottom-up) controls across the landscape (Perry et al. 2011). In a single mixedseverity fire event, some forest patches burn at high severity, killing most of the trees, while some patches burn at a lower severity leaving mostly live trees. Over time, a forest with a mixed-severity fire regime could experience a combination of low and high severity fires resulting in mean fire intervals of ca. 20 and 32 years in dry mixed-conifer (DMC) stands (Tepley and Veblen 2015; Heyerdahl et al. 2019) and MMC (Tepley and Veblen 2015) stands, respectively. These variable patterns of fire, over space and time, contribute to a complex landscape mosaic of fine-scale forest patches with varying structure and composition (Taylor and Skinner 1998). These variable fire patterns, including the presence of high severity fire, can also remove and create patchiness of fire history evidence, which contributes to the difficulty of reconstructing historical fire in these mixedseverity fire landscapes (Tepley and Veblen 2015). Correspondingly, stand development in these patches that experienced variable fire patterns can be equally complex. For instance, individual tree species may play multiple successional roles, where the proportion of shade-intolerant and shade-tolerant trees in post-fire cohorts can vary substantially depending on the pre-fire 
landscape, the severity and size of fire that a patch experiences (Tepley et al. $2013 \& 2014)$ and the microclimatic conditions of the stand or patch (Tepley and Veblen 2015), among other things. Though often overlooked in traditional schools of thought (e.g. Agee 1993; Johnson et al. 2001; Franklin et al. 2002), considering a more complex successional framework is an important component in understanding the disturbance dynamics in mixed-severity fire regime forests.

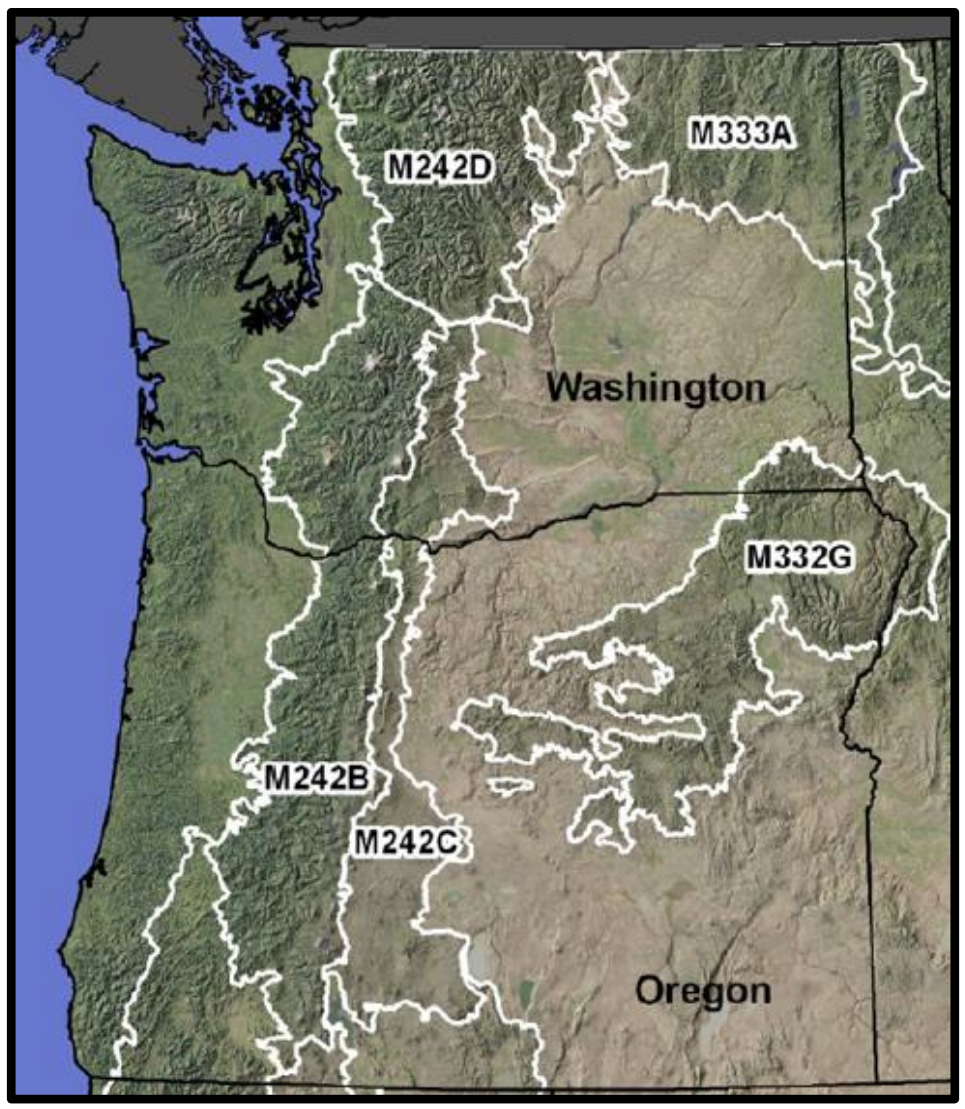

Figure 2. Bailey Sections and Subsections in Oregon and Washington, USA with forest vegetation types that exhibit mixed severity fire regimes (adapted from Perry et al. 2011; Bailey 2009). Section codes are as follows: M242D (Northern Cascades), M33A (Okanogan Highlands), M332G (Blue Mountains), M242B (Western Cascades), and M242C (Eastern Cascades).

To overcome the many challenges with reconstructing historical, pre-fire suppression fire patterns in mixed-severity fire regime forests, previous studies 
have implemented a multi-proxy approach, combining dendroecological (i.e. tree ring) data with forest structure interpretations from historical aerial photographs (Naficy et al. 2015; Naficy 2016). The forest stands (i.e. patches) delineated from the aerial photos are direct observations of spatial patterns of forest structure created by the interaction of previous disturbances with biophysical conditions (Hessburg et al. 1999). One of the many attributes assigned to each patch is a structural classification based on stand development processes (O'Hara et al. 1996). Stand structure tends to be a better surrogate of historical fire regimes than other vegetation classifications (potential vegetation type, ecological succession seres, phytosociology, etc.) because it is less sensitive to fine-scale variations in site conditions such as soils and microclimates that are common in rugged mountainous terrain (O'Hara et al. 1996; Tepley and Veblen 2015; Naficy 2016). By sampling dendroecological data within these forest patches, where within-patch variation of age structure and disturbance histories is expected to be less than between patches, spatiotemporal fire severity-mediated dynamics can be illustrated more accurately (Naficy 2016). If these patches do indeed represent ecologically meaningful units, which calibration by empirical (i.e. dendroecological) data is needed to confirm, then these data could be used to develop a structure-based fire severity model to better understand historical and current disturbance patterns at a landscape scale (e.g. Hessburg et al. 2007).

There is evidence that fire exclusion and past land management has caused forests over much of the western US, including those with mixed-severity fire regimes, to become more homogeneous in structure and composition 
(Hessburg et al. 2000). This homogeneity may expose these forests to a host of problems, including increased susceptibility to insect infestation and higher fire severity than historically due to increased fuel loading and continuity. There is debate, though, regarding the extent to which fire exclusion has caused departures from the natural range of variability in these forested ecosystems, how forest change may impact current or future forest resilience, and whether or not restoration is appropriate (Odion et al. 2014; Hanson et al. 2015; Hessburg et al. 2016).

Intersection of complexities - Moist mixed-conifer forests with mixed-severity fire regimes

Fire exclusion-mediated changes in forest structure and composition in the western US are well documented in dry ponderosa pine forests that historically experienced frequent, low severity fire (e.g. Swetnam and Baisan 1996; Hessburg et al. 2005). However, there are far fewer studies documenting fire exclusion effects in MMC forests in the Northwest US that historically experienced mixed severity fire regimes (Stine et al. 2014). In mesic forests, species composition is dominated by less decay-resistant trees than in dry forests and/or those that are poor fire recorders (e.g. grand fir; Howard and Aleksoff 2000; Tepley and Veblen 2015). This, in combination with the difficulties associated with studying mixed-severity fire regimes, makes it remarkably challenging to find and interpret evidence of historical fire patterns in these forests. 
The Blue Mountains Ecoregion (BME) in northeastern Oregon and southeastern Washington is host to a network of MMC forests that occur along a mid-elevation band within the region and intermix on north-facing slopes with lower elevation dry mixed-conifer forests (Figure 3; Stine et al. 2014). MMC forests encompass over $46 \%$ of the area of the Blue Mountains (Hessburg et al. 2019), and yet, much of the dendroecological (i.e. tree ring) reconstructions of fire history have focused on the dry mixed-conifer forests within the BME, and moist forests that lie on the margin of drier forests (e.g. Heyerdahl et al. 2001 \& 2019, Merschel et al. 2014 \& 2018, and Johnston 2016).

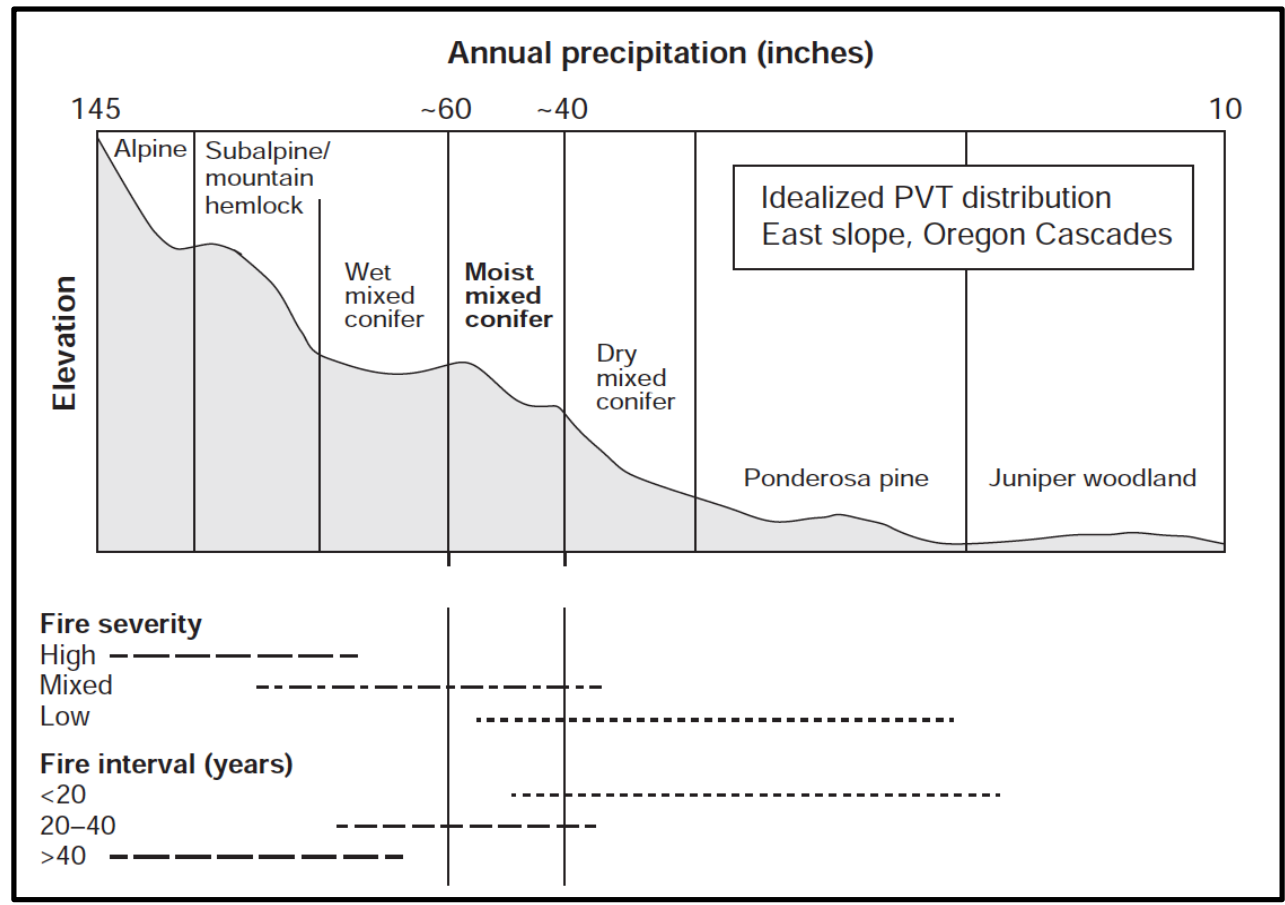

Figure 3. Continuum of forest types found along an elevational gradient on the east side of the Cascade Range in the northwestern US and the relationship of forest type to general fire regimes. PVT = potential vegetation type (from Stine et al. 2014).

Additionally, less of the work done in the region and elsewhere across the western US has involved a quantitative reconstruction of the natural range 
of variation of fire severity (but see Tepley and Veblen 2015 in DMC stands in the southern Colorado Rockies and Heyerdahl et al. 2019 in DMC forests in Central Oregon). Fire severity is an important component in the fire regime and associated forest succession dynamics (Turner 2010; Tepley et al. 2013), including in MMC forests (Stine et al. 2014). And while there is some evidence that mixed-severity fire regime forests' current structure and composition lie outside their natural range of variation (due to the combined effects of climate change, timber harvest and fire exclusion; e.g. Hessburg et al. 2016), very few studies have quantified the structure and composition of these forests prior to the fire suppression era (but see Tepley and Veblen 2015). Thus, the need for reference conditions of historical fire patterns lies at the intersection of complexities, in the MMC forests that are expected to have experienced mixedseverity fire regimes.

The objective of this study was to characterize the variability in historical fire patterns and tree establishment within MMC forests expected to have experienced a mixed-severity fire regime within the BME. We asked: (1) What were the patterns in composition and timing in tree establishment over the past couple centuries, and how did these relate to fire events and historical drought conditions? We hypothesized that shade-intolerant tree recruitment would correspond to fire events and be less sensitive to climate, whereas shadetolerant tree recruitment would not be in sync with fire events but instead to anomalously wet climatic conditions; (2) What were the fire patterns (i.e. frequency, severity) in this forest over the past couple centuries? We 
hypothesized that historical fires in these MMC stands occurred relatively infrequently (e.g. 50-200-year intervals) and that fires would have been a mix of severities, with more severe fires being less common and corresponding to wetter stands; and (3) What is the degree of variability in the historical fire and tree establishment patterns at the landscape scale (i.e. among forest patches) and how does climate (i.e. moisture and snowpack) covariate with variability in these patterns across the study area? We hypothesized that historical fire and tree establishment patterns occurred at fine scales, and that forest stands would exhibit unique fire histories. To test these hypotheses, we used a multi-proxy approach combining aerial photography interpretation, fire scar and tree recruitment dates, and mathematical modeling to reconstruct fire history, quantify fire severity, and qualitatively compare fire, tree establishment, and climate relationships across two subwatersheds in a MMC forest of the northern BME. 


\section{Approach/Methods}

\section{Study area}

This study was conducted in the Blue Mountains Ecoregion (BME) of northeastern Oregon, United States (Figure 4). The BME is the largest ecoregion in Oregon, encompassing roughly 24,000 square miles of geologically diverse and dissected topography that extends into the neighboring states of Idaho and Washington.

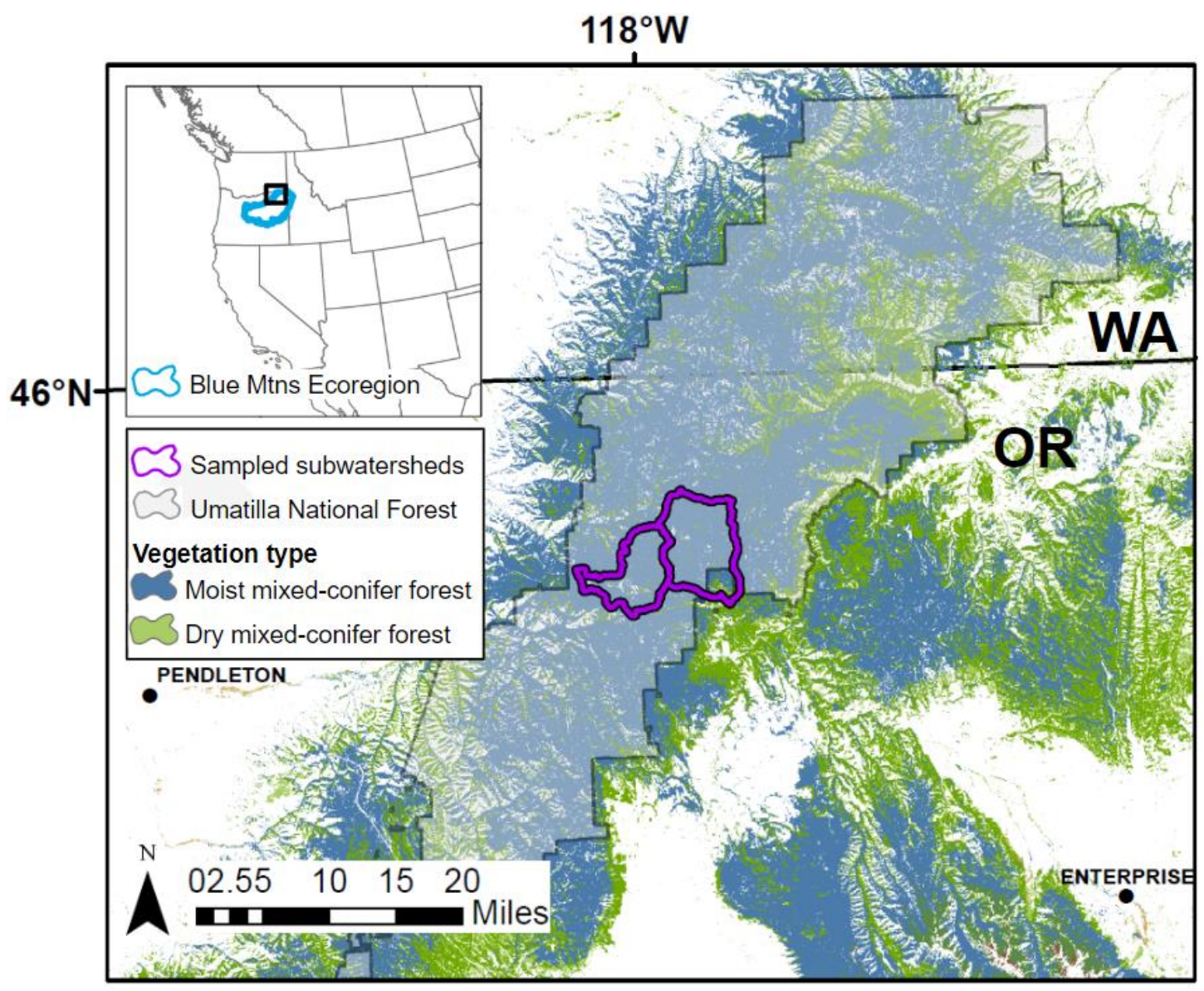

Figure 4. Location of study area and two sampled subwatersheds, Upper Lookingglass Creek (left) and Little Lookingglass Creek (right) within the Blue Mountains ecoregion of northeastern Oregon, USA.

The ecoregion currently supports an economy dominated by wood products and cattle production, as well as wheat and alfalfa in low-elevation river valleys 
(Oregon Conservation Strategy, 2016). For thousands of years, Native Americans intentionally burned parts of the landscape to enhance food production, but the spatial extent and intensity of this activity is unknown (Hessburg and Agee 2003). Euro-Americans arrived in the region around 1850, and began the process of fire exclusion shortly thereafter (Agee 1996; Boyd 1999). They set cattle out to graze, which removed fine fuels and decreased the ability of fire to ignite and spread. By the early 1900s logging began, also removing fuel. And by the 1940s active fire suppression was widespread in the region.

The Blue Mountains, the largest mountain range within the ecoregion, are characterized by plateaus and isolated uplifted mountain peaks dissected by steep river canyons, and a north-south climatic gradient. The northern portion of the range experiences more precipitation than the southern portion due to its proximity to the Columbia River, which channels moisture from the Pacific Ocean (Mock 1996).

The study area is located within the MMC forests in the northern portion of the Blue Mountain range in the Upper and Little Lookingglass Creek subwatersheds (Figures 4 \& 5). These subwatersheds encompass approximately 9,300 ha total, and the plots ranged in elevation from 1,166 to $1,578 \mathrm{~m}$ with a variety of slope angles and aspects represented (Figure 6). The study area is characterized by a continental climate with warm and dry summers, and cold winters, with the majority (90\%) of precipitation occurring during the winter months in the form of snow. Across the study area, average monthly 
temperatures range from 15.5 to $18.3^{\circ} \mathrm{C}$ in July and -3.7 to $-0.5^{\circ} \mathrm{C}$ in January

(PRISM, 2019). The average annual precipitation ranges from 628.2 to 1343.7

mm (PRISM, 2019; Western Regional Climate Center, 2019).
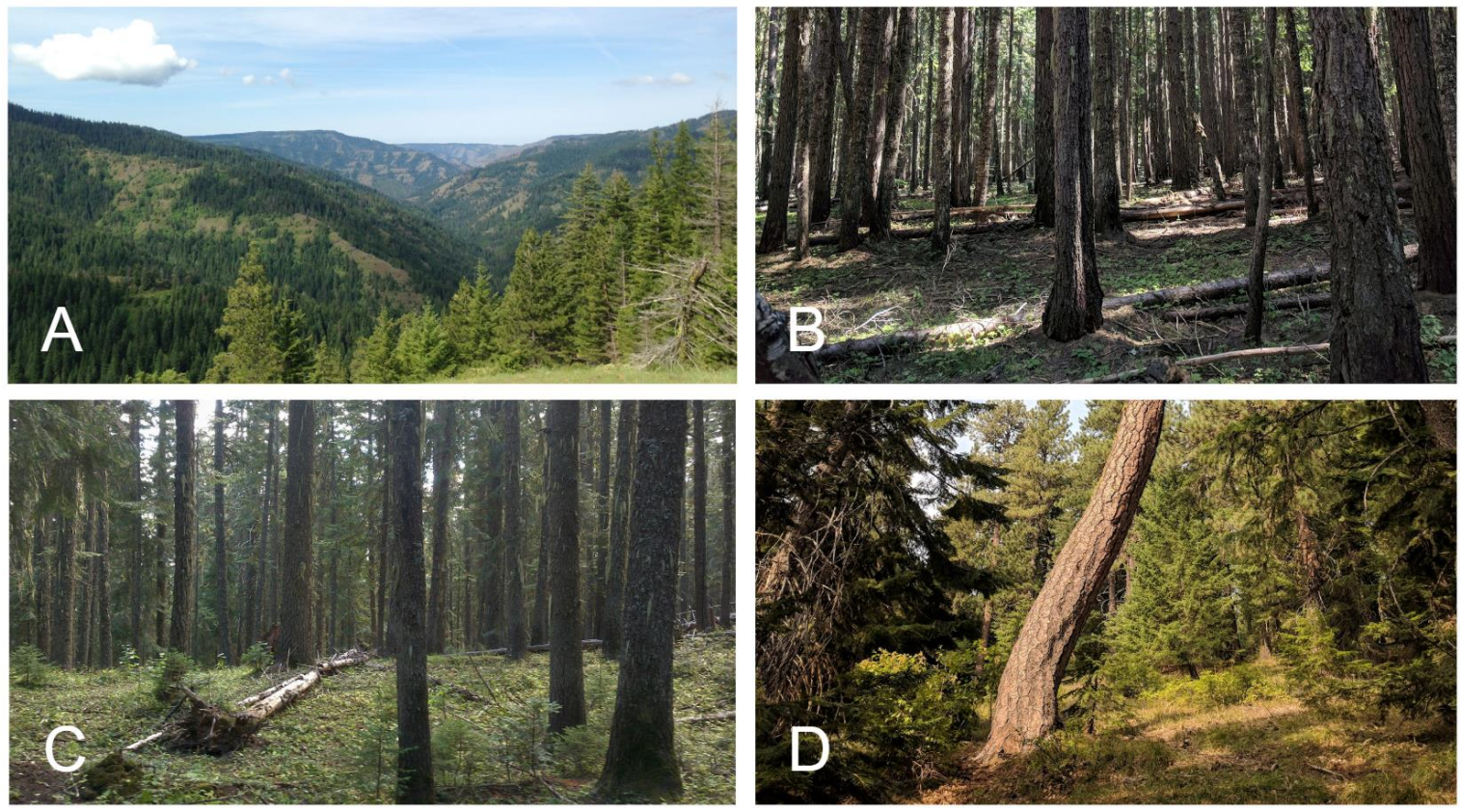

Figure 5. Photos depicting (A) the dissected landscape characteristic of the northern Blue Mountains, (B) a sampled site in the 'Cool Moist Forest', (C) a site in the 'Cool Wet Forest', and (D) a site in the 'Warm Dry Forest' potential vegetation classifications (Powell et al. 2007). Photo credits: Laura Platt. 
A

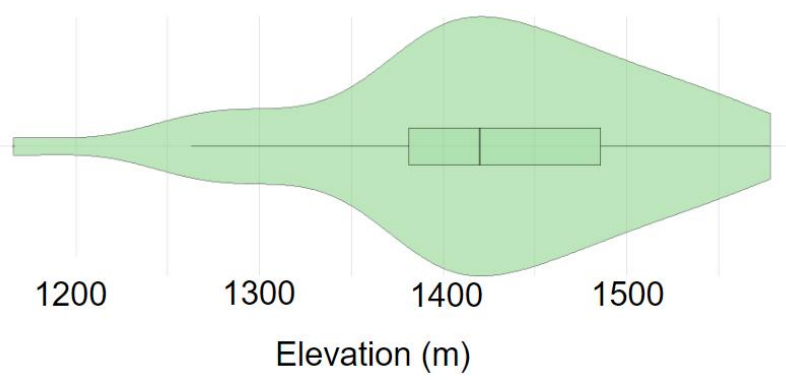

B

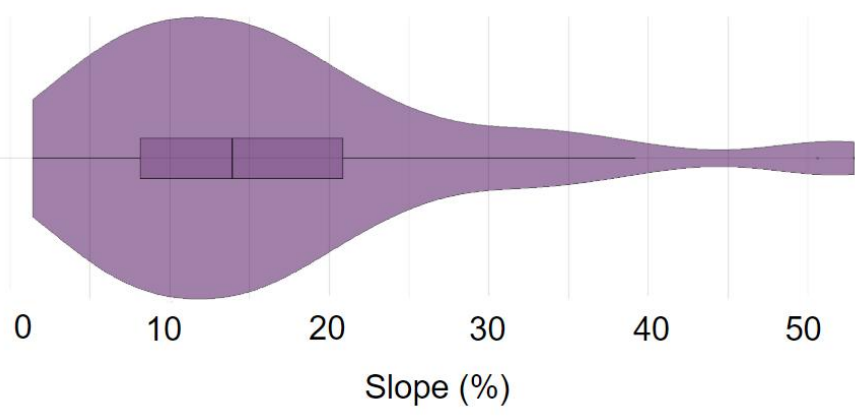

C

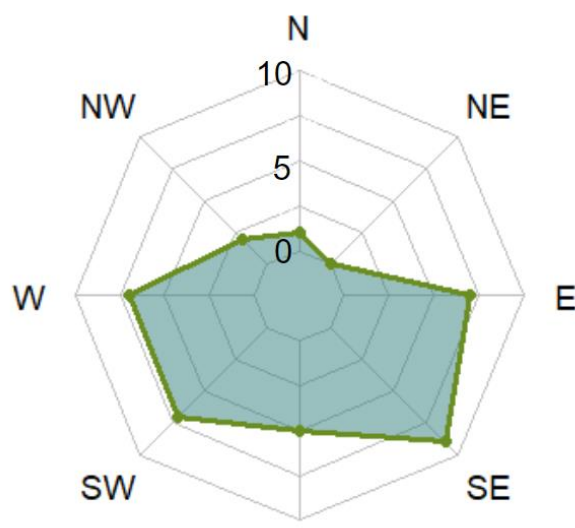

$S$

Figure 6: Topographic distribution of sampled plots in the Jubilee Lake study area by $(A)$ elevation, (B) slope, and (C) aspect. Aspect scale is from 0 plots at the center to 10 plots at the outside. $\mathrm{n}=38$.

Plots were sampled within a mix of potential vegetation classifications (Powell et al. 2007) from 'Cool Wet Upland Forest' (Figure 5A), to 'Warm Dry Upland Forest' (Figure 5B), with a majority of our sites within the 'Cool Moist Upland Forest' classification (Figure 5C). The dissected landscape in this region is conducive to a fine-grained forest mosaic, where the forest composition changes abruptly with topography (Stine et al. 2014). The forests at the sampled sites generally include a mix of grand fir (Abies grandis Dougl. ex D. Don Lindl.), western larch (Larix occidentalis Nutt.), Engelmann spruce (Picea engelmannii Parry ex Engelm.), and a minor component of Douglas-fir (Pseudotsuga menziesii (Mirb.) Franco), ponderosa pine (Pinus ponderosa Lawson \& C. Lawson), and lodgepole pine (Pinus contorta Douglas ex Loudon). Lodgepole 
pine in the study area might include serotinous (var. latifoliada) and nonserotinous (var. murrayana) populations. Of the common tree species present, the shade-tolerant species include grand fir and Engelmann spruce. The shadeintolerant species include western larch, lodgepole pine, ponderosa pine, and to a lesser degree, Douglas-fir (Abrahamson, USFS Fire Effects Information System). Both shade-tolerant tree species present are less adapted to fire than shade-intolerant tree species, which are adapted to cope with frequent/low severity events (western larch, ponderosa pine, Douglas fir) and infrequent/midhigh severity events (serotinous lodgepole pine).

\section{Sampling approach}

A multi-proxy sampling scheme was used to reconstruct historical patterns of fire and tree establishment in the northern BME (Table 1; Agee 1996). Since fires of mixed severity, both over space and time, affect the landscape differently than fires of low severity or high severity alone, they require unique sampling approaches (Fulé et al. 2003; Speer 2010; Schoennagel et al. 2011; Heyerdahl et al. 2012; Tepley and Veblen 2015). Specifically, a combination of tree ages and fire scar data sampled across photo-interpreted forest patches provide a more complete and accurate reconstruction of historical fire patterns than either of these proxies alone (Kent 2014; Appendix A). Additionally, pairing of the fire dates from fire scars and the tree age-structure data allowed for the calculation of 
a fire severity index; a mathematical function of tree density declines after each historical fire over time (Tepley and Veblen 2015).

Table 1. Data collected in this study

\begin{tabular}{|l|l|}
\hline Sample/ Data source & Parameter \\
\hline Fire scar samples & $\begin{array}{l}\text { crossdated calendar fire dates (\# and \% } \\
\text { scarred trees per year) }\end{array}$ \\
\hline Tree core samples & $\begin{array}{l}\text { tree establishment dates per species (tree } \\
\text { density/time) }\end{array}$ \\
\hline
\end{tabular}

In order to capture as much of the variability in fire processes across the landscape as possible, a stratified random sampling approach was used to allocate the sampling efforts across patches with distinct forest structure (O'Hara et al. 1996) as delineated and interpreted from pre-fire suppression era aerial photos from the 1930s (Hessburg et al. 1999; Figure 7). Each patch was assigned a structural class (O'Hara et al. 1996; Table 2) and was sampled according to its proportional area in each subwatershed. For example, if the understory reinitiation structural type made up $\sim 26 \%$ of the area of the subwatershed, approximately one quarter of the total patches sampled were understory reinitiation patches. 

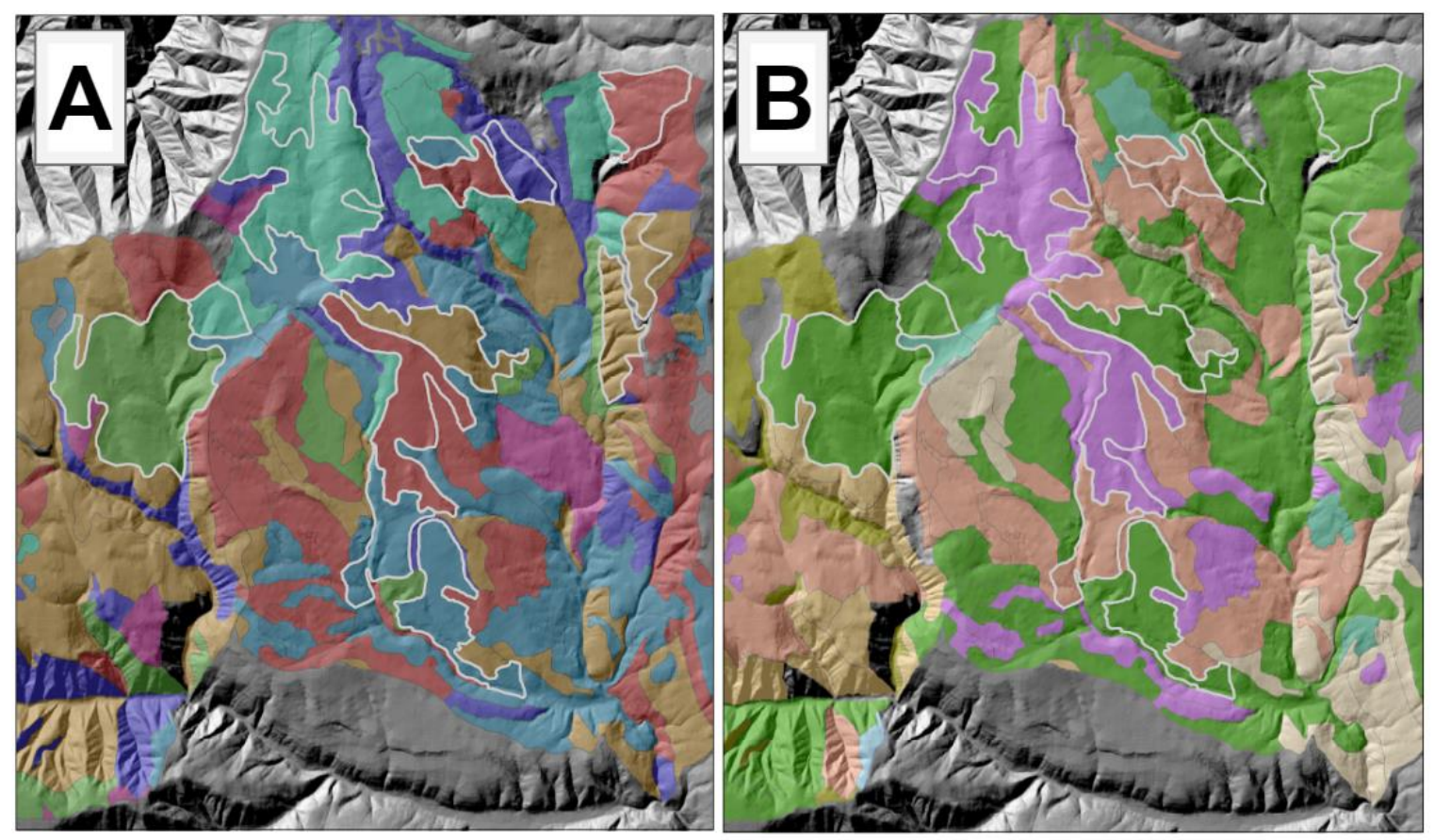

\section{Forest structure classes}

understory reinitiation $(26 \%)$

stem exclusion closed canopy $(25 \%)$

young forest multi-story $(16 \%)$

stand initiation (15\%)

3 stem exclusion open canopy (11\%)

3 old forest multi-story (3\%)

3 old forest single story $(3 \%)$

\section{Overstory species}

$$
\begin{aligned}
& \text { ABGR }(44 \%) \\
& \text { PSME }(22 \%) \\
& \text { LAOC }(18 \%) \\
& \text { PIPO }(13 \%) \\
& \text { PICO }(<1 \%)
\end{aligned}
$$

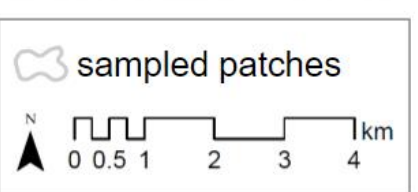

Figure 7: Sampled patches in the Lookingglass Creek subwatersheds stratified by $(A)$ forest stand structure and $(B)$ dominant overstory species composition, as interpreted from historical aerial imagery (Hessburg et al. 1999). Percent area in the Little Lookingglass Creek subwatershed represented by each structural class and overstory species are shown. Grand fir (ABGR), subalpine fir (ABLA), western larch (LAOC), lodgepole pine (PICO), Engelmann spruce (PIEN), ponderosa pine (PIPO), and Douglas-fir (PSME). Forest structure classes and overstory species reconstructed outside sampling areas are shown for landscape context. 
Table 2. Structural types along a successional gradient (O'Hara et al. 1996) and respective sampling intensity are listed in increasingly higher structural complexity. Number of plots to be sampled per structural patch type was predetermined as a function of structural complexity with more plots in more complex structural types.

\begin{tabular}{|l|l|c|c|}
\hline Structural type & Description & $\begin{array}{c}\text { \# sample } \\
\text { plots/patch }\end{array}$ & $\begin{array}{c}\text { \# tree } \\
\text { cores/patch }\end{array}$ \\
\hline Stand initiation & $\begin{array}{l}\text { Recently disturbed; dominated by a } \\
\text { single cohort of seedlings/saplings }\end{array}$ & 2 & 30 \\
\hline $\begin{array}{l}\text { Stem exclusion, } \\
\text { closed canopy }\end{array}$ & $\begin{array}{l}\text { Dense forest of small trees, often with } \\
\text { a single cohort }\end{array}$ & 2 & 30 \\
\hline $\begin{array}{l}\text { Stem exclusion, } \\
\text { open canopy }\end{array}$ & $\begin{array}{l}\text { Open forest with small trees of similar } \\
\text { size }\end{array}$ & 3 & 45 \\
\hline $\begin{array}{l}\text { Understory } \\
\text { reinitiation }\end{array}$ & $\begin{array}{l}\text { Relatively closed canopy forest } \\
\text { comprised by patches with different } \\
\text { age classes, two or more cohorts }\end{array}$ & 3 & 45 \\
\hline $\begin{array}{l}\text { Young forest, } \\
\text { multistory }\end{array}$ & $\begin{array}{l}\text { Low density forest dominated by small } \\
\text { and medium sized trees. Intermediate } \\
\text { to high complexity }\end{array}$ & 4 & 60 \\
\hline $\begin{array}{l}\text { Old forest, single } \\
\text { story }\end{array}$ & $\begin{array}{l}\text { Old forest with single size class, one or } \\
\text { more cohorts present }\end{array}$ & 4 & 60 \\
\hline $\begin{array}{l}\text { Old forest, } \\
\text { multistory }\end{array}$ & $\begin{array}{l}\text { Forest comprised by patches with } \\
\text { different age and size classes, } \\
\text { including patches with large, old trees }\end{array}$ & 4 & 60 \\
\hline
\end{tabular}

Field sampling intensity increased with increasing complexity of patches, where a higher number of plots were located in forest patches with greater structural complexity (e.g. old forest multistory; Table 2). In order to capture pre-fire exclusion forest composition and structure, the field crew avoided sampling in areas that, since the aerial-photo interpretative work, were known to have experienced timber harvest or fire. 
Field methods

To characterize the age structure of trees expected to have established prior to fire exclusion (defined here as $\geq 10 \mathrm{~cm}$ diameter at breast height $[\mathrm{DBH}]$ ), increment cores were extracted from targeted trees in two diameter size classes: 'large' and 'small'. Due to high intra-patch variation in structure and composition, the specific diameter range and thresholds assigned to 'large' and 'small' trees were determined by the existing tree species composition and size (DBH) structure at the plot level. Cores were collected in each plot from the 15 (ten 'large' and five 'small') closest trees to each plot center. Species and DBH of each cored tree were recorded, and the distance from plot center to the farthest tree sampled was measured for both the large and small size class plots in order to calculate tree density. In order to avoid missing growth rings and attain the most accurate estimate of establishment dates, coring of trees was conducted as close to the ground as possible and coring height was recorded. Increment cores were checked in the field to ensure presence of the tree's pith, or proximity to pith (i.e. presence of central rings estimated to be within five years of pith). If the tree's pith was missed, another core was obtained from the same tree and the best core out of up to five attempts was kept. In cases where a tree was too rotten (approximately $15 \%$ of sampled trees) to produce useful information, a substitute tree of the same species and similar $\mathrm{DBH}$ was sampled outside of the plot. 
To correct tree ages for coring height, ca. 10 saplings $(<4 \mathrm{~cm} \mathrm{DBH})$ per species were harvested, processed in the lab (see below), and used for building a size-age regression. To establish a more accurate estimate of growth rates to correct for coring height, sapling harvesting was conducted in environmental conditions (e.g. open canopy for shade-intolerant species) similar to those expected to have been experienced during the establishment of the sampled adult trees (Villalba and Veblen 1997).

Sampling of fire scars was conducted opportunistically when hiking to and from the age structure plots, as well as during extensive searches within sampled patches and in areas bordering patches likely to produce fire-scarred trees. Fire scars were collected with a chainsaw in partial cross-sections, and in order to minimize impact on living trees, dead trees were targeted for sampling where possible. Intact fire scars were rare (33\% of sampled trees); most scarred trees encountered were rotten grand fir (Appendix A). Where possible, between 5-10 partial cross-section samples were collected per patch.

\section{Sample processing}

All dendroecological samples were processed in the lab using standard procedures (Stokes and Smiley 1968). Tree cores, harvested saplings, and fire scar samples were sanded with sequentially finer grades of sandpaper (up to 1000 grit) until the cellular structure was visible under a microscope. The samples were scanned using an Epson Expression 11000XL between 12002400dpi and annual rings were delineated using CooRecorder (Cybis Elektronik, 
2010). To ensure dating accuracy, samples were cross-dated visually using the list-year method (Yamaguchi 1991) and statistically with CDendro (Cybis

Elektronik, 2010). Master tree ring chronologies for each species sampled were created in order to increase accuracy in statistical crossdating.

To correct for core samples where pith was missed, the Duncan method was used to estimate the number of missing rings to pith (Duncan 1989). Each core was also assigned a confidence categorical classification of one through six based on crossdating accuracy and the Duncan estimation. For instance, a core with high confidence in crossdating accuracy and pith present would be assigned a confidence code of one, whereas a core that was not able to be crossdated, or that had Duncan estimate greater than 30 years would be assigned a confidence code of six. The establishment dates of trees that were of lowest confidence (confidence code of six; $8 \%$ of all samples) were modeled using a locally created, size-age regression (within forest patch) for each species. Establishment dates were estimated for 569 of the 570 cores collected. At the time of data collection, $94 \%$ of the sampled trees were alive.

\section{Data analysis}

For analyses, tree establishment dates were binned by decade due to potential deviations from true pith, despite corrections for coring height and missing pith. Because tree establishment patterns were congruent/consistent among plots per patch and fire histories could not be determined at the plotscale, tree age structure is reported per patch. To identify years of substantial 
tree establishment for each species per patch, cohort peaks were identified using a modified version of CharAnalysis (Andrus et al. 2018). This peak detection algorithm initially created to detect peaks from background charcoal in sediment cores (Higuera 2009) has been successfully used to detect peaks in tree establishment (e.g. Tepley and Veblen 2015; Andrus et al. 2018). In order to explore the relationship between tree establishment and climate, a graphical (qualitative) comparison was conducted between all tree establishment (and identified peaks) and a local PDSI reconstruction (Cook et al. 2008).

Due to scarcity of intact fire scar samples, fires were reconstructed and analyzed at the patch (as opposed to plot) scale. Fire events were attributed to an individual patch only if the scarred tree in question was within the delineated patch boundary or a maximum distance of $276 \mathrm{~m}$ away from the patch's closest age structure plot (i.e. median value of the distance distribution between crosssection samples to closest age structure plots; Figure 8). For patches lacking fire scar evidence entirely (four of 13 patches), in most cases due to heart rot, tree establishment peaks as well as fire scar evidence from neighboring patches were used to identify likely fire dates for that patch. Beyond Euclidean distance, fire barriers were also considered in these attributions; e.g. if a major drainage lies between the cross-section sample and the patch, the fire event would less likely be attributed to the patch in question. Fire dates were compiled into FHX file format and analyzed with Fire History Analysis and Exploration System (FHAES) and graphed with the burnr package in the $\mathrm{R}$ statistical environment (Brewer et al. 2016; Malevich et al. 2018). 


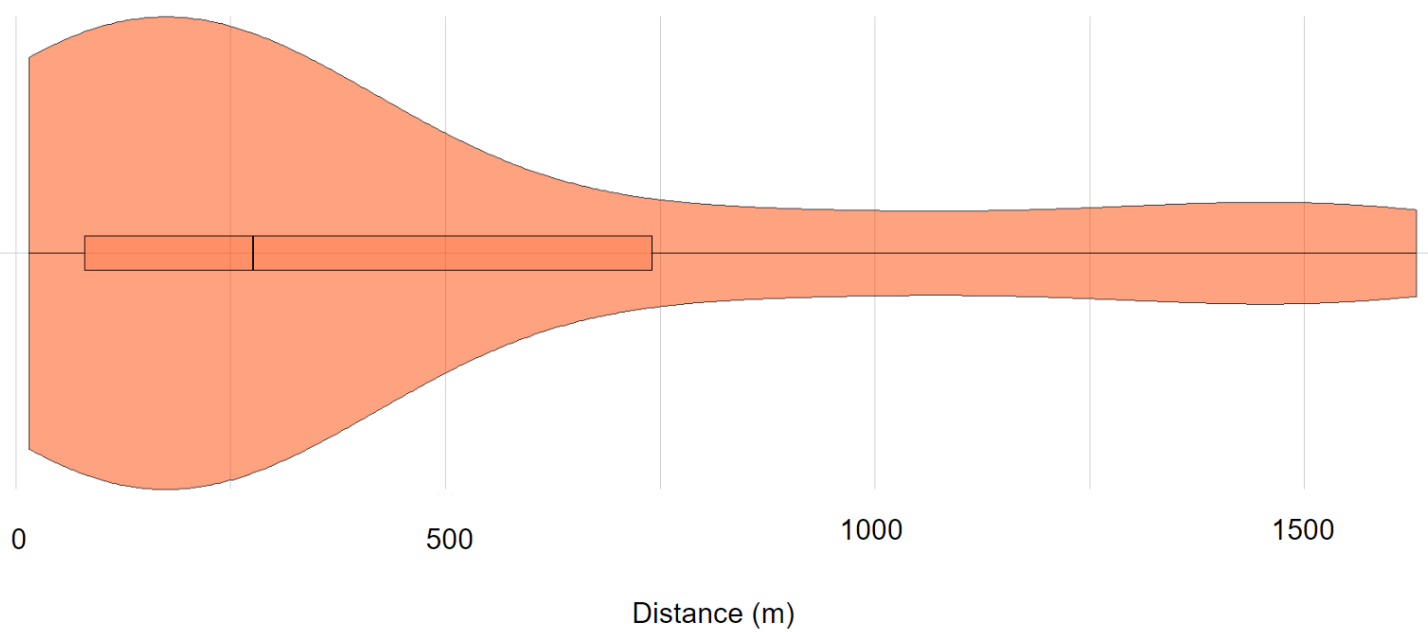

Figure 8. Distribution of distances $(\mathrm{m})$ between sampled fire scar cross-sections and nearest age structure plot, $n=33$. Median is $276 \mathrm{~m}$, upper quartile is $740 \mathrm{~m}$, and lower quartile is $80 \mathrm{~m}$.

To quantify historical fire frequency, mean and median fire intervals for each patch were computed using traditional aggregation filters of fire-scarred trees, including all fire years (composited by patch) and widespread fire years (years in which at least $30 \%$ of all fire recording trees [i.e. trees that had previously recorded at least one fire before that date] recorded a fire, and at least two patches recorded the fire). Only scar-to-scar intervals were used. To quantitatively reconstruct historical fire severity, relative, event-level fire severity metrics and classes were calculated following methods in Tepley and Veblen (2015) and Naficy (2016), where the age structure and fire record of each patch are used to quantify the rate of loss in forest stand density with each fire event (Appendix B). 


\section{Results}

Across two subwatersheds, 38 age-structure plots were sampled in 13 unique forest patches representing six different forest structural types (Table 3, Figure 9). In total 570 tree core samples, 55 saplings, and $>100$ fire scar partial cross-sections were collected to reconstruct patch-level fire frequency and severity in complex MMC patches across various environmental settings and from the margins of dry mixed conifer forest to cold forest vegetation types.

\section{Historical tree establishment}

The majority (66\%) of reconstructed tree establishment in forest patches in the Lookingglass Creek subwatersheds occurred between 1880 and 1930 (Figure 10A) though peaks in establishment were identified in nearly every decade and varied in frequency and timing by patch (Figure 10B). Tree establishment abundance was dominated by grand fir ( $59 \%$ of cores collected) regardless of decade or patch, and post-fire establishment of grand fir cohorts was common (Figure 10B \& 14). Grand fir dominated the post-fire tree recruitment in nine (53\%), and was present in 16, of the 17 post-fire cohorts identified (i.e. establishment peaks within the same decade, or decade following, a fire attributed to that patch). Establishment peaks not associated with fire were not as common as post-fire peaks, but were observed in five of 13 patches and comprised eight of 25 (32\%) total identified establishment peaks (Figure 10B). Establishment of other tree species over the time series, including Engelmann spruce $(17 \%$ of cores) and western larch (13\% of cores) were also common. A 
minor component of recorded tree establishment included Douglas-fir (5\%), lodgepole pine (4\%), ponderosa pine (2\%), and subalpine fir (1\%).

Over the ca. 200 years that the tree establishment record spans, little to no association appears to exist between establishment peaks and historical moisture (or drought) conditions, as reconstructed by the closest (northeastern Oregon) PDSI index (Figure 10C; Cook et al. 2008).

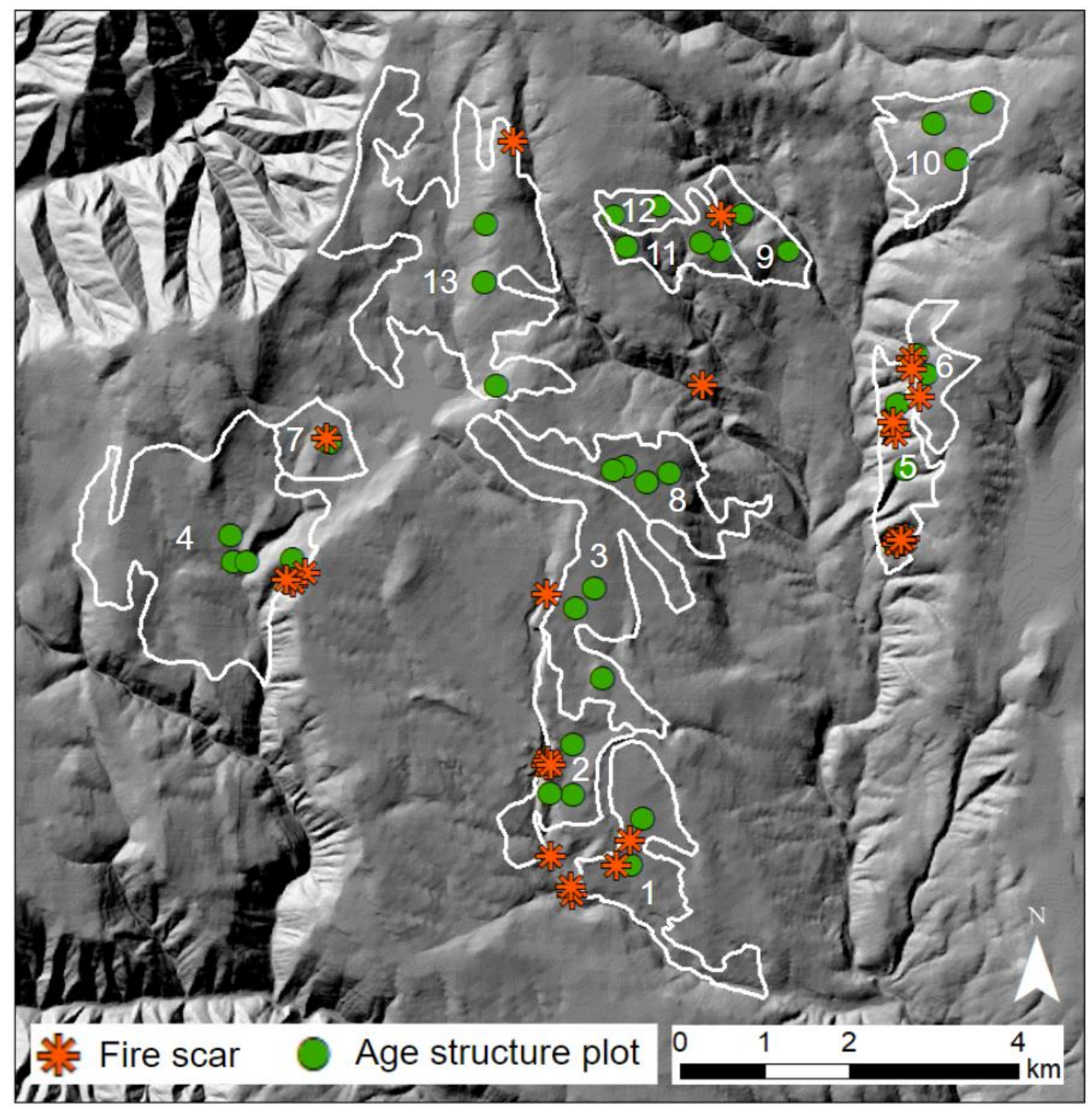

Figure 9. Map of sampled patches with age structure plots and fire scars across the Lookingglass Creek subwatersheds. Patches are numbered in order of increasing elevation (1=lowest, $13=$ highest). 


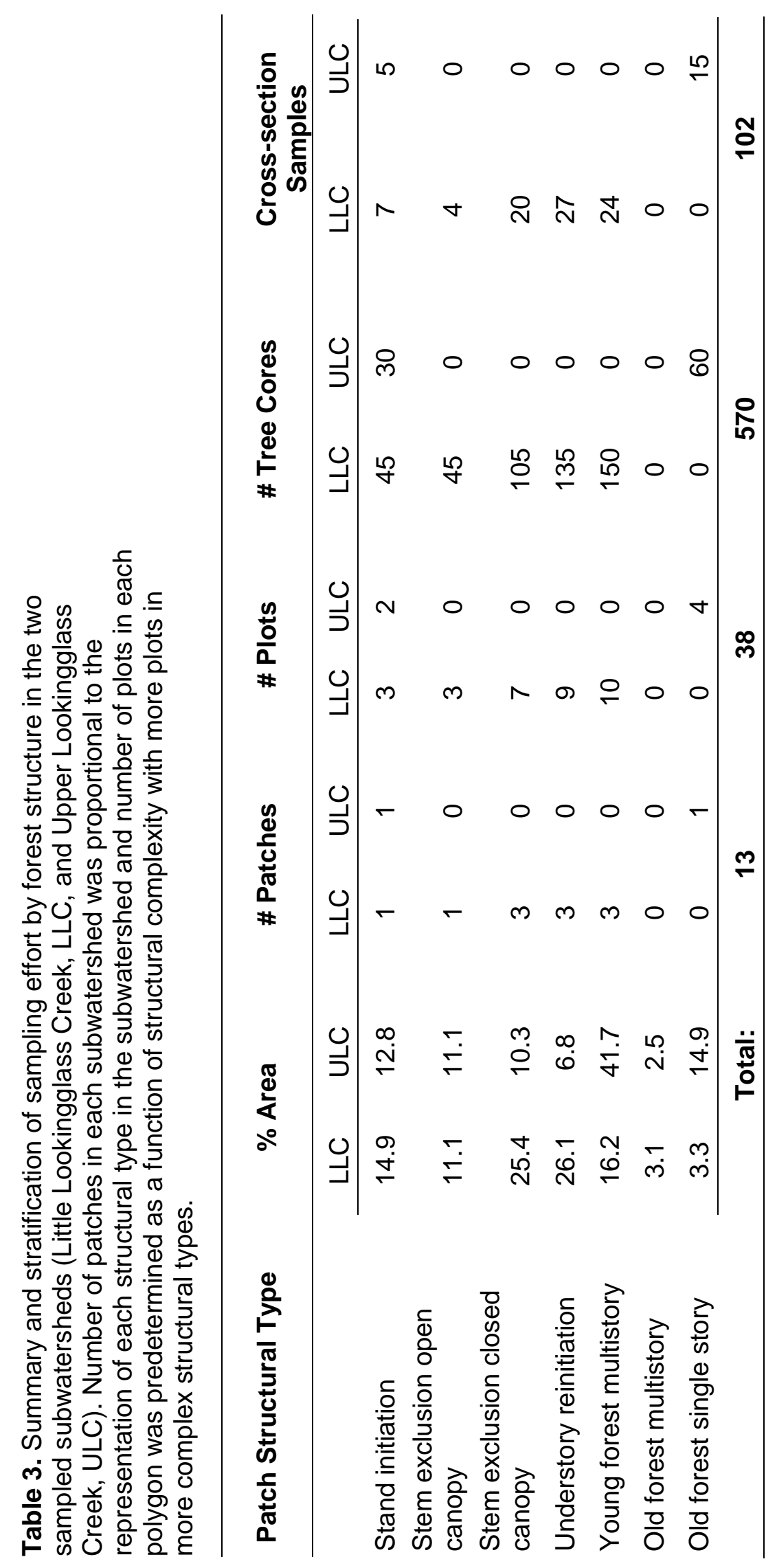




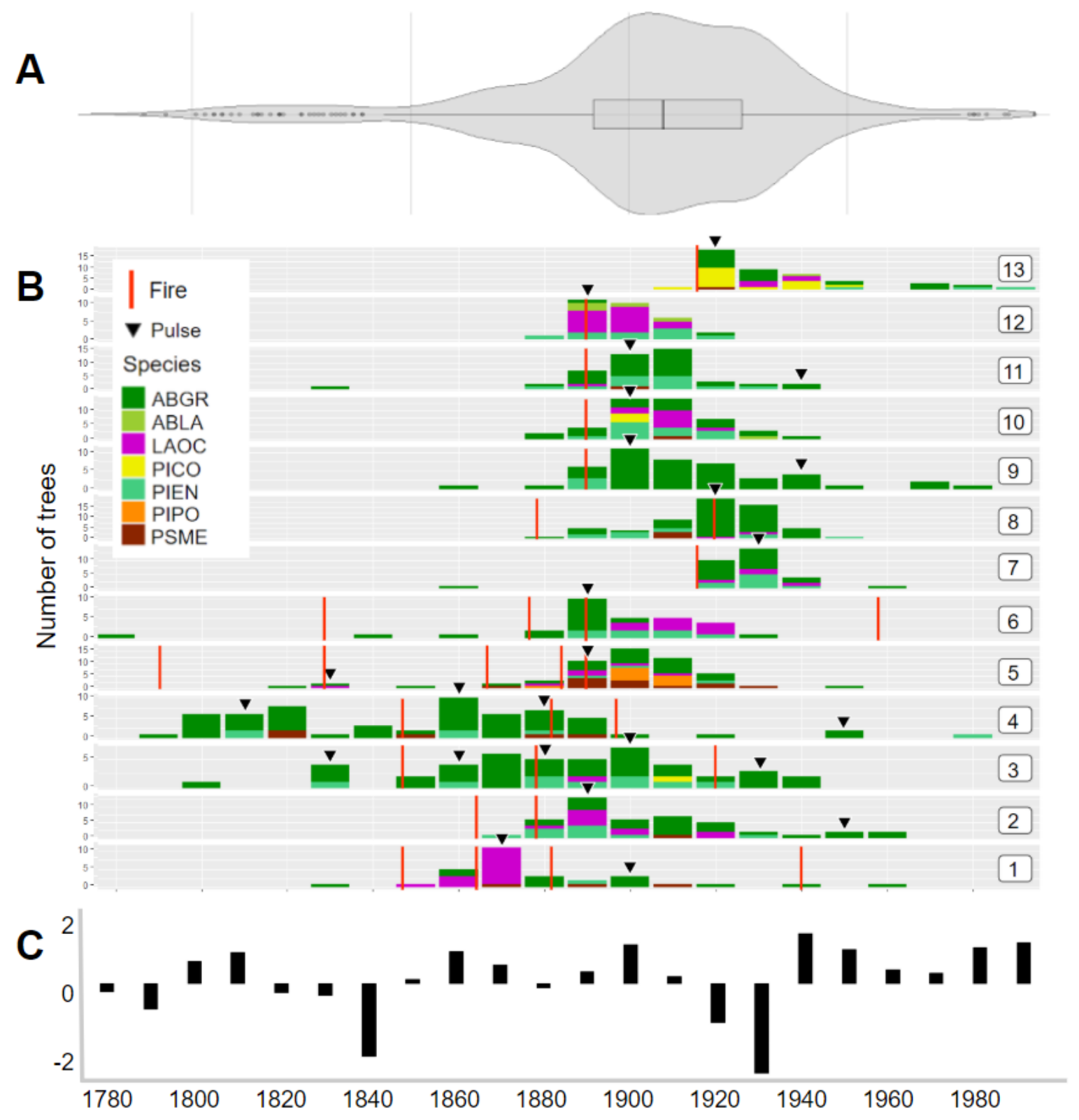

Figure 10. (A) Violin boxplot of establishment dates $(n=569)$ across all patches. Median establishment date for all trees cored is 1908 (solid black bar), lower quartile is 1892 and upper quartile is 1926. (B) Establishment demography and fire events for each of the 13 sampled patches. Patches are in order of increasing elevation (1=lowest, 13=highest) and correspond to patches numbered in Figure 9. Establishment dates are binned by decade. Black triangles above bars indicate significant pulses in tree establishment as identified using a modified version of CharAnalysis (Higuera 2009; Andrus et al. 2018). Species abbreviations are as follows: Grand fir (ABGR), subalpine fir (ABLA), western larch (LAOC), lodgepole pine (PICO), Engelmann spruce (PIEN), ponderosa pine (PIPO), and Douglas-fir (PSME). Three PIPO trees, not shown in the figure above, established in 1520, 1536 and 1570 in the patch with other PIPO present. (C) Decadal zscores of Palmer Drought Severity Index (PDSI), a meteorological drought index. The 
annual PDSI values were obtained from a dendroecological reconstruction by Cook et al. (2008), averaged by decade to match establishment bins, and converted to z-scores. Negative values indicate drier than average conditions and positive values indicate wetter than average conditions.

\section{Historical fire frequency and occurrence}

Altogether, 48 fire scars were identified on 29 crossdated partial crosssection samples (Figure 11) in the Lookingglass Creek subwatersheds. There was an average of 1.6 scars per sample (maximum 4 ), with $52 \%$ of the samples having only one scar. Of the trees sampled for partial cross-sections, $52 \%$ were alive at the time of sampling. Ponderosa pine accounted for the largest portion $(62 \%)$ of fire scar samples, followed by Douglas-fir (14\%), western larch (14\%), lodgepole pine (7\%), and grand fir (3\%). The initial sample set of 102 partial cross-sections consisted of approximately $45 \%$ Grand fir, but due to rot and high uncertainty of fire years, most of these were excluded from further analysis (Appendix A).

Fires in the Lookingglass Creek subwatersheds were recorded from 1765 to 1958 , and overall were relatively common in the record, especially around the second half of the $19^{\text {th }}$ century (1869-1883). Few events were recorded prior to 1800 and the chronology is mostly fire-free after the 1900 s; less than $13 \%$ of all crossdated fire scars were formed after 1902 (Figure 11). In the study area, the availability and quality of fire scar samples generally decreased with elevation. Due to a scarcity of fire scar evidence, several patches (six out of 13 ) did not 
have enough scar to scar data (one or less recorded fire events) to calculate intervals.

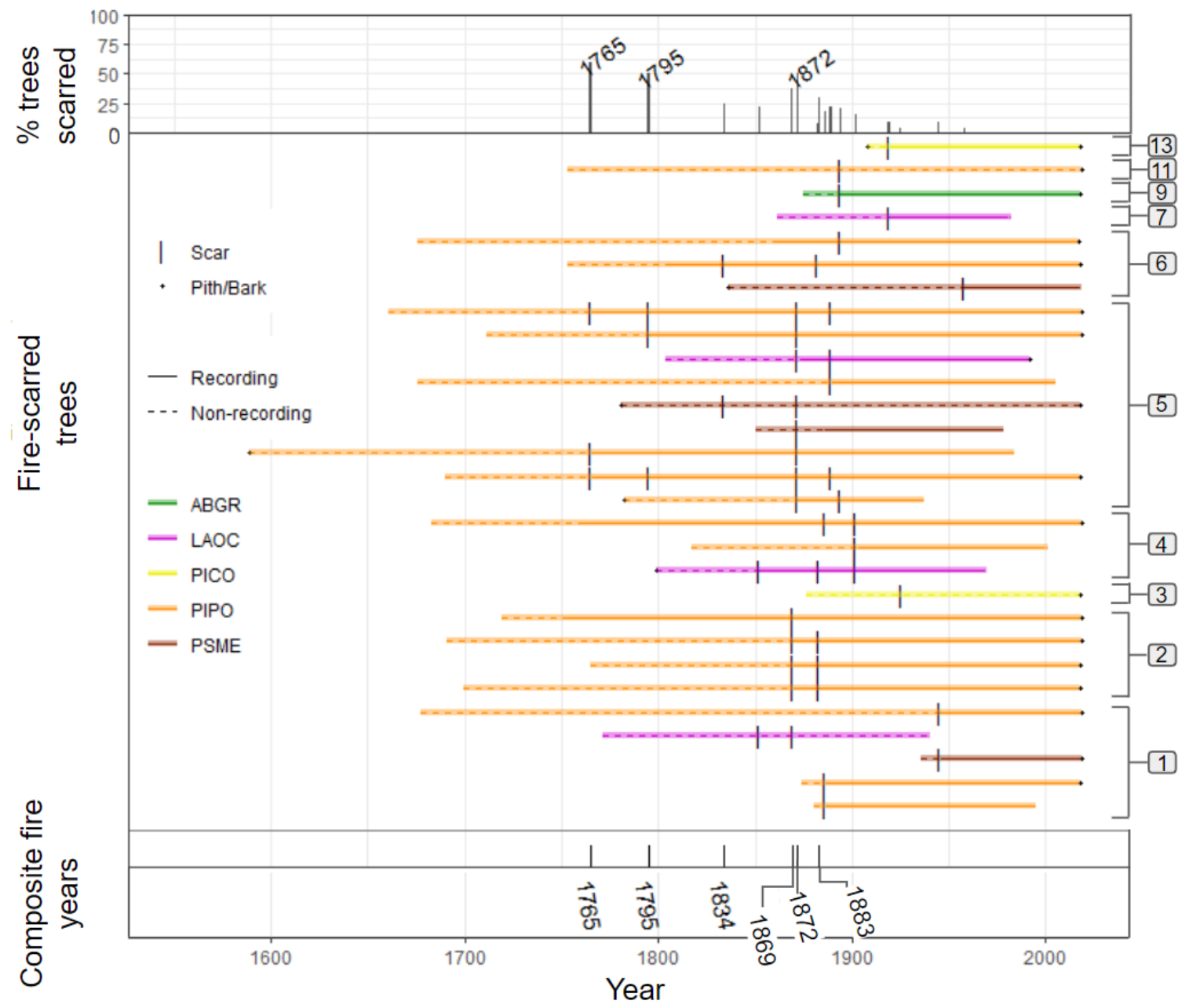

Figure 11. Chronologies of fire scars for the Upper and Little Lookingglass Creek subwatersheds. Each horizontal line represents one partial cross-section sample, colored by species $(\mathrm{ABGR}=$ grand fir, $\mathrm{LAOC}=$ western larch, $\mathrm{PICO}=$ lodgepole pine, $\mathrm{PIPO}=$ ponderosa pine, and PSME $=$ Douglas $-\mathrm{fir}$ ) and ordered by elevation of sample (top $=$ highest). Brackets group individual scarred trees (sampled cross-sections) by patch. Patches are in order of increasing elevation (1=lowest, 13=highest) and correspond to patches numbered in Figure 9. A composite fire chronology at the base of the figure shows fire years where at least $25 \%$ of all recording trees recorded fire and at least two trees were scarred. Composite fire event years in the Lookingglass Creek subwatersheds included 1765, 1795, 1834, 1869, 1872, and 1883. 
At the subwatershed scale, a total of 30 fire events were reconstructed in the 13 sampled patches. Of these 30 events, successfully cross-dated fire scar samples were used in $23(77 \%)$ events and were also found in nine of the 13 sampled patches (69\%; Figure 12). The remaining seven events (23\%) in five patches lacked fire scar samples (fire scar evidence was found in all five of these patches, but we were unable to collect intact samples; Appendix A) and thus were attributed fire dates by using both co-occurring peaks in tree establishment and matching dates in neighboring patch fire scar samples (Figure 12). Out of the nine patches that recorded and had intact fire scars (69\%), the mean and median number of fire events were ca. 2.5 and 2 , respectively, whereas ca. 1.4 and 1 events were recorded for the remaining patches.

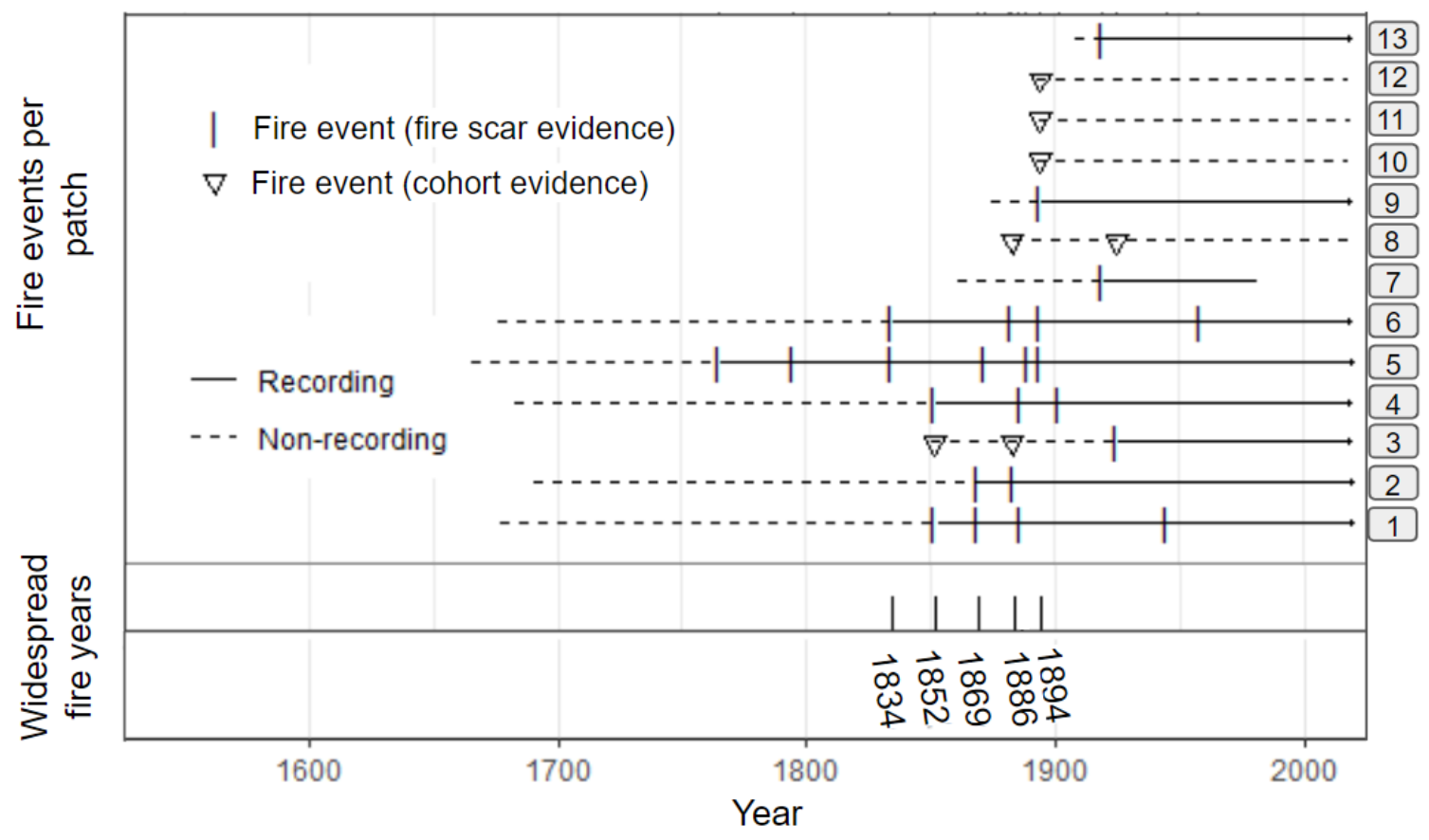

Figure 12. Fire demography chart for the Lookingglass Creek subwatersheds. Each horizontal line shows a composite of fire events for a patch. Patches are in order of increasing elevation ( $1=$ lowest, $13=$ highest) and correspond to patches numbered in Figure 9. Fire events are recorded in each patch as solid vertical black lines. Open 
triangles are fire years that were attributed to a patch based on neighboring patch fire scar evidence, and the establishment peak of a cohort of regenerating trees. A subwatershed-scale composite plot at the base of the figure shows widespread fire years: fire years where at least $30 \%$ of all patches recorded a fire event in that year, with a minimum of two patches recording the fire. Widespread fire years: $1834,1852,1869$, 1886, 1894.

The fire patterns were relatively fine-scale in the two subwatersheds, where in many years there was evidence of fire in one patch and no evidence of fire in an adjacent patch. Across the study area, the widespread fire years were: $1834,1852,1869,1886$, and 1894, with no single fire year recorded in all patches. The most widespread fire year was recorded in six (46\%) of patches in 1894, after which no widespread fires were recorded.

Across patches, fires were more frequent than anticipated, with mean fire intervals ranging from 14 to 42 years (median: 14 - 48 years) with an average patch size of approximately 200 ha. Furthermore, mean fire frequency, where calculated, did not vary greatly across a moisture gradient in the study area (Figure 13). Yet, large variability was found between individual minimum and maximum intervals of individual events amongst patches, where the minimum fire interval was five years, and the maximum was 64 years. Both the minimum and maximum fire intervals (recorded in patches \#5 and \#6, respectively; Figure 13) were in the middle of the distribution of patches along a moisture gradient of the study area. Though, the minimum interval was recorded in the only patch with substantial presence of ponderosa pine in the canopy overstory, and the only patch within the 'Warm-Dry Upland Forest' in the potential vegetation classification. 


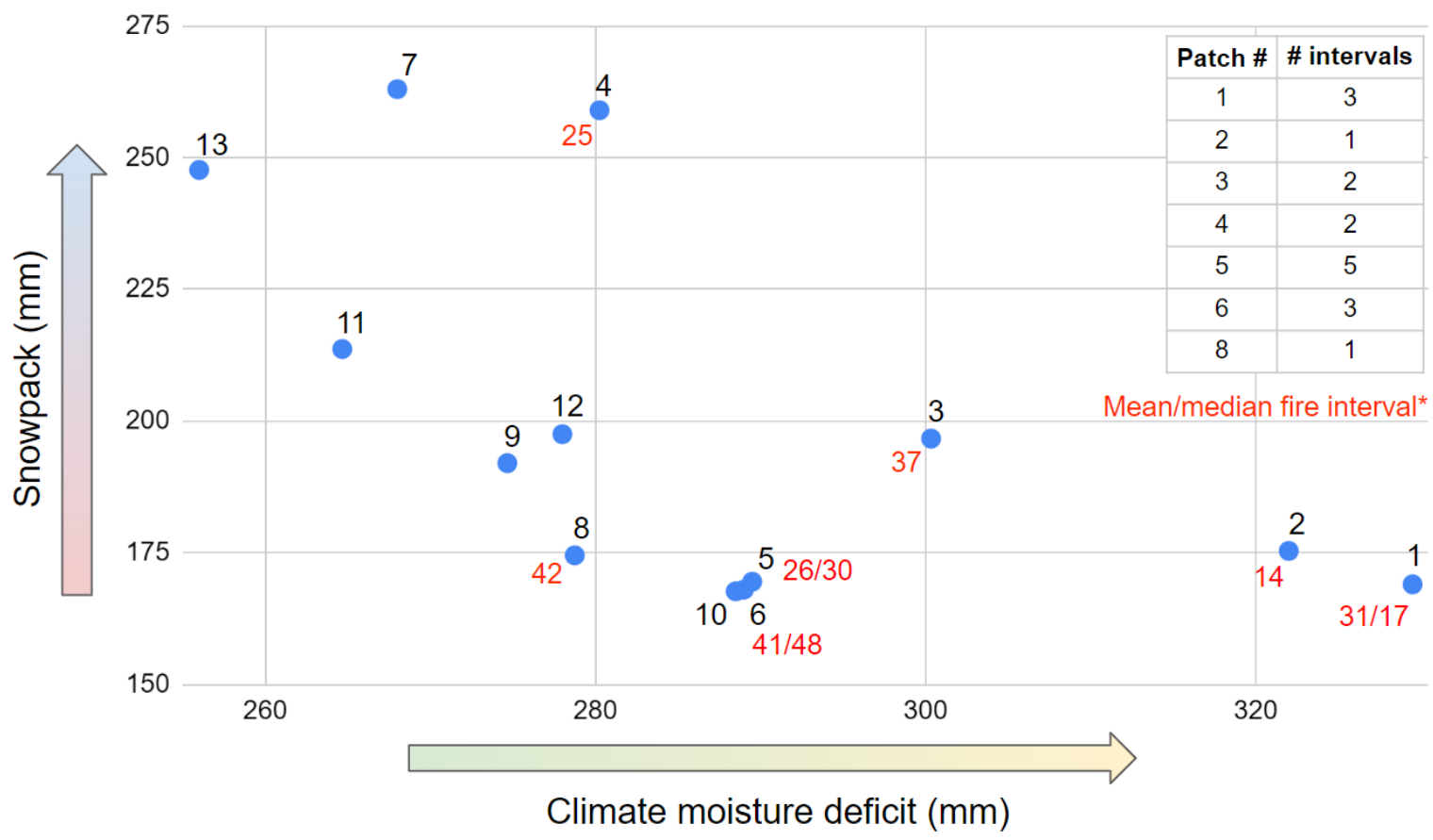

Figure 13. Calculated fire intervals for sampled patches shown along a moisture gradient. Patches are numbered in order of increasing elevation (1=lowest, $13=$ highest). Climate data were calculated using ClimateNA (Wang et al. 2016) for the reference normal 1961-1990 period. The $x$ and y axes are summer Hargreaves climate moisture deficit in millimeters, and winter precipitation as snow in millimeters, respectively. ${ }^{*}$ Where there is only one value provided for the fire interval, the mean and median were the same.

\section{Historical fire severity}

Fire severity exhibited fine-scale variation over space and time in the study area. Adjacent patches often burned with different severities in the same year (e.g. patch \#s 10, 6 and 5 in Figures 9 \& 14). Likewise, fire severity within patches varied over time with different fire events (e.g. patch \#s 1, 2 and 3 in Figure 14). A majority of the patches (77\%) experienced at least one high severity fire, though no single high severity fire event was recorded across more than four sampled patches. Presence of fire was also apparent throughout the study area on living, fire-scarred trees (Appendix A), and many patches that experienced a high severity fire also experienced either a low or moderate severity fire, or both. 

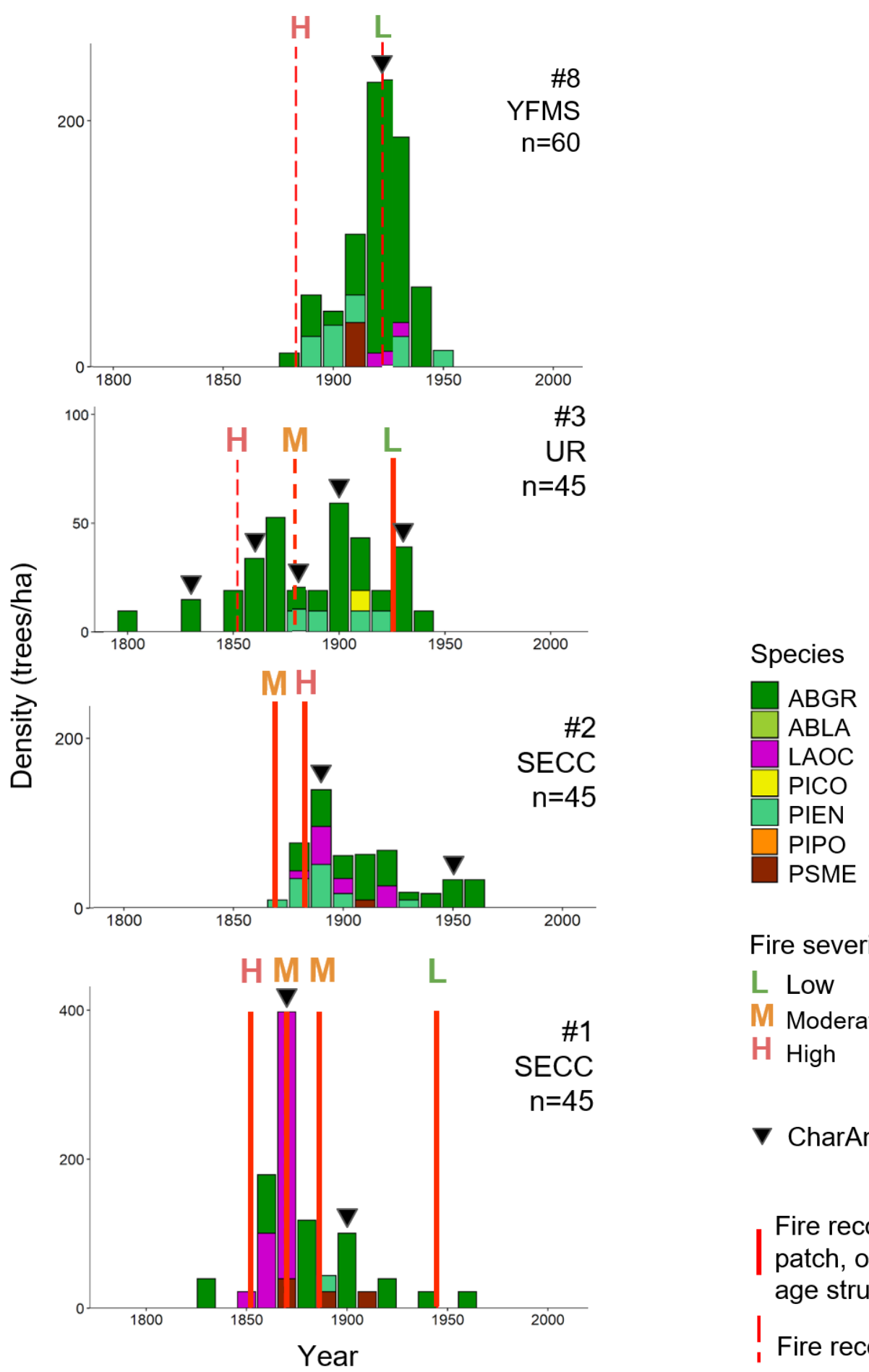

Fire severity

L Low

M Moderate

$\mathrm{H}$ High

$\boldsymbol{\nabla}$ CharAnalysis pulse

Fire recorded within patch, or within $276 \mathrm{~m}$ of age structure plot , Fire recorded locally

Figure 14. Fire history and age structure of sampled patches. The patch number (corresponding to map in Figure 9) and structural type, as well as the number of pith dates (i.e. core samples) are indicated in the upper right corner of each panel. Fire scars found on partial cross-sections within $276 \mathrm{~m}$ (median value of distance distribution) of the closest age structure plot and fire events attributed to a patch based on cohort data and neighboring patch fire scars (i.e. fires recorded locally) are represented by solid red 
lines, and dashed red lines, respectively. The cohort peaks and severity of individual fires are also indicated. Species and structural type abbreviations are as follows: Grand fir (ABGR), subalpine fir (ABLA), western larch (LAOC), lodgepole pine (PICO), Engelmann spruce (PIEN), ponderosa pine (PIPO), and Douglas-fir (PSME); old forest single story (OFSS), stem exclusion closed canopy (SECC), stem exclusion open canopy (SEOC), stand initiation (SI), understory reinitiation (UR), and young forest multistory (YFMS).
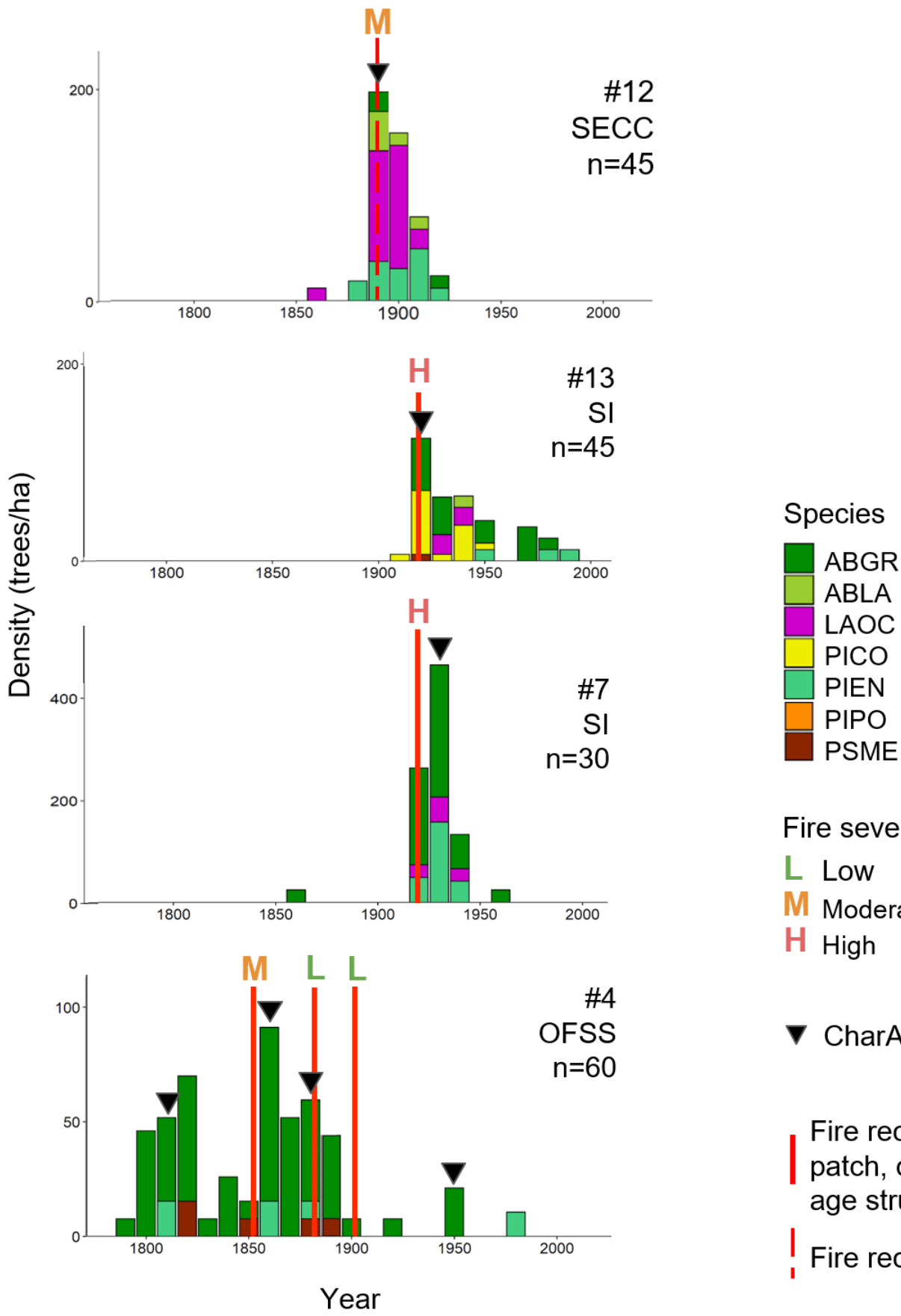

Fire severity

L Low

Moderate

H High

$\boldsymbol{\nabla}$ CharAnalysis pulse

Fire recorded within patch, or within $276 \mathrm{~m}$ of age structure plot

Fire recorded locally

Figure 14. Continued. 
Species

\begin{tabular}{l}
$\square$ ABGR \\
ABLA \\
LAOC \\
$\square$ PICO \\
PIEN \\
\hline PIPO \\
PSME
\end{tabular}

Fire severity

L Low

M Moderate

$\mathrm{H}$ High

$\boldsymbol{\nabla}$ CharAnalysis pulse

Fire recorded within patch, or within $276 \mathrm{~m}$ of age structure plot

, Fire recorded locally
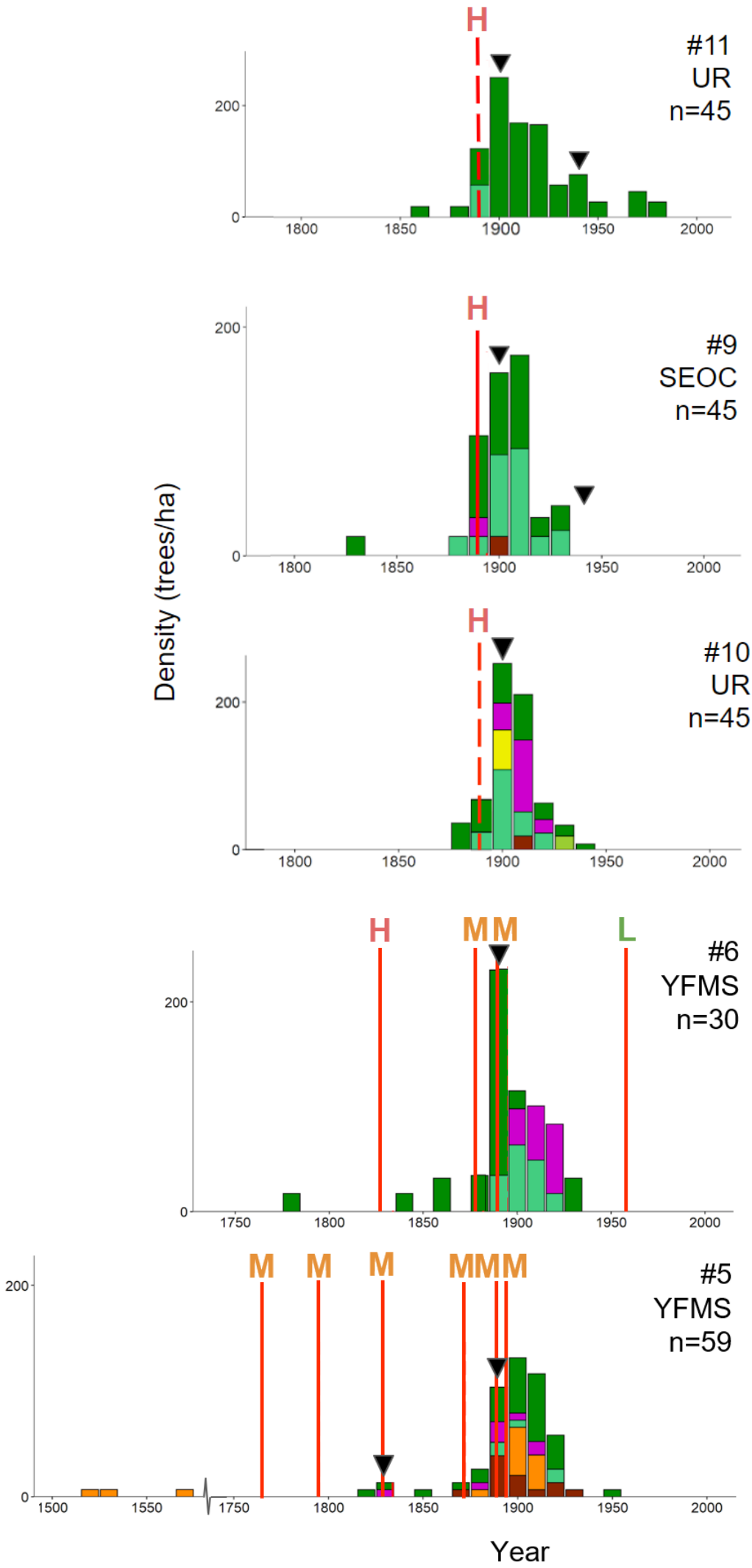

Figure 14. Continued. 


\section{Discussion}

Historical fire occurrence, tree establishment, and fire severity patterns were highly variable at a fine scale (hundreds of hectares) in the MMC forests of the Lookingglass Creek subwatersheds in the Northern Blue Mountains (e.g. Figures 10B \& 14). Presence of small, high severity fires was common in the landscape, with no single high severity event recorded across the entire 9,300 ha study area. Such high variability in fire frequency, severity and size is consistent with the meso-scale patch heterogeneity characteristic of mixed-severity fire regimes. In these MMC forests interacting top-down (climate) and bottom-up (topography) controls co-determine fire patterns at relatively fine scales (Perry et al. 2011). Even so, these historical fire patterns appear to be even more finescale (i.e. less spatially synchronous across the study area) than in other fire history studies in mixed-severity fire regime forests (e.g. Tepley and Veblen 2015; Heyerdahl et al. 2019). This may be partly due to scarcity of intact fire scar evidence, and dominant trees (mostly grand fir) being poor fire recorders within the study area, as this study area is substantially more productive (wetter) than sites in these previous studies, especially in comparison to Central Oregon (Heyerdahl et al. 2019). Nonetheless, a larger fire scar sample depth might instead have confirmed the high variability and fine-scale patterns found in this study. The highly dissected topography typical of the BME, where steep drainages and rocky slopes interrupt the continuity of surface fuels and isolate forest patches, may limit fire spread, also contributing to these fine-scale patterns (Stine et al. 2014). Additionally, complex forest stand structure may have played 
an important role in influencing historical fire behavior and the spatial variation and arrangement of subsequent forest patches. The variable nature of the historical fire patterns in these forests would have likely perpetuated these disturbance and forest development processes over time, with each successive fire reinforcing, subdividing, or overwriting the forest structural patterns at fine scales (Tepley et al. 2013).

In patches with two or more events, fires were more frequent than anticipated within the MMC forest (Figures $11 \& 12$ ) and mean fire intervals, where calculated, did not deviate much across moisture gradients within the study area (Figure 13). Notably though, intact fire scar samples decreased with increasing elevation (e.g. patch \#s 5, 6 and 10 in Figures 13 \& 14), including the six patches that recorded just a single, recent high severity fire that might have instead erased earlier fire evidence. These patches were at relatively high elevation within the subwatersheds, and on the cooler/wetter end of the climatic gradient within the study area, thus potentially fitting the climate-limited, high severity fire regime model (Figure 13). However, the frequent fire reconstructed in most (seven of thirteen) patches is counter to fire ecology theory that suggests fires were relatively infrequent (i.e. 50-200-year return intervals) in these midelevation, moist forests (Agee 1996; Brown et al. 2004). The findings in this study are consistent with regional syntheses (e.g. Stine et al. 2014) and recent studies within the BME and in drier surrounding forests (e.g. Johnston et al. 2016, Merschel et al. 2018) that document relatively frequent fires in DMC to MMC forests. 
Few events were recorded prior to 1800 in the study area (Figures 11 \& 12), which may be due to lack of intact, dead and older recorder trees to reconstruct earlier fires. Alternatively, there could have been a large standreplacing fire prior to 1800 in the subwatersheds that removed evidence of prior fire. However, there is little evidence in the current dataset (in the form of tree recruitment pulses or otherwise) to support this scenario. There was a notable decrease in fire activity after 1900 across the two subwatersheds. The last widespread fire was recorded in 1894, though there is evidence of some local and isolated events after this date. This aligns with the timing of an abrupt decrease in fire activity observed in other studies within the BME (e.g. Heyerdahl et al. 2001; Merschel et al. 2014; Johnston et al. 2016) and is likely explained by the effects of fire exclusion in the region (Hessburg et al. 1999). Fire has not been entirely excluded from the northern Blue Mountains, however, and a handful of fires have occurred in the $21^{\text {st }}$ century in the Umatilla National Forest outside of our study area. According to wildfire perimeters recorded by the Monitoring Trends in Burn Severity Program (MTBS; Eidenshink et al. 2007), these recent fires appear to be more widespread (i.e. larger) than any fire events that we were able to reconstruct in this study. The lack of fire in this study area since the turn of the 20th century, which likely played a significant role in creating and sustaining patch heterogeneity historically, has probably contributed to a more homogeneous, densely forested landscape, as found in other studies in the region (e.g. Johnston 2017). 
Tree establishment peaks composed of primarily shade-tolerant species (e.g. grand fir and Engelmann spruce) were the dominant regeneration dynamic following fire events in the study area (Figures $10 \& 14$ ). This was observed for fire events across all patches and all calculated severity levels. These findings highlight potentially incorrect applications of the relay floristics model in MMC forests, where it is generally understood that these shade-tolerant species are common components of late seral stages in the forest community, and that their presence is indicative of a long period since fire (Agee 1996). Instead, this study's results support the framework of the initial floristics model (Egler 1954). The prolific presence of grand fir as an early seral species has been documented in post-fire regeneration studies within the Blues (Morgan et al. 2015; Downing et al. 2019) and elsewhere in the northwestern US (Cobb et al. 1993; Kemp et al. 2016; Busby 2019). Though Engelmann spruce is known to regenerate post-fire (Uchytil 1991), it is less often mentioned in the literature than grand fir. For grand fir and Engelmann spruce to be present in a post-fire cohort, a few surviving trees must have been present locally as a seed source as these species are unable to re-sprout (Howard and Aleksoff 2000). In another study, presence of grand fir seedlings post-fire was found to be probable as far as $165 \mathrm{~m}$ from a live seed tree (Kemp et al. 2016). Although grand fir is a prolific seed producer and disperser, the abundant grand fir regeneration that we documented initiating post-fire further indicates that patch size of historical high severity fire events was unlikely to be extensive, and provides further evidence of fine-scale patch heterogeneity at these sites. At a big-picture scale, these results may question 
the use of eco-physiological classes based on ability to grow and thrive under shade for inferring post-fire establishment traits. These findings at least suggest additional pathways to think about vegetation dynamics, specifically to expand the current post-fire paradigm of relay floristics for one that also incorporates initial floristics (e.g. Tepley et al. 2014). These findings also encourage the consideration of the complexity of mixed fire patterns over time and its effects on post-fire tree establishment and stand development (e.g. Tepley et al. 2013).

Across the six different patch structural types sampled, there was a variety of unique fire histories and establishment patterns associated with each (Figure 14). In a majority of cases, the fire history and subsequent tree establishment patterns corroborated the structural classification for the patch developed from aerial photo interpretation, and in some the alignment was not as clear (Figures 14 \& 15). For example, the two stand initiation patches (patch \#s $13 \& 7$ in Figure 14) both exhibit a history of one high severity fire and a subsequent, abrupt pulse of establishment. This aligns with the description of this structural type, where a single cohort reoccupies a space following a stand-replacing disturbance (Hessburg et al. 1999). The one sampled old forest single story patch (patch \#4 in Figure 14) exhibits a pattern of multi-cohort establishment beginning in the late 1700 s, and experienced numerous nonlethal fires. This also aligns with the structural classification by Hessburg et al. (1999). One of the three sampled understory reinitiation patches (patch \#10 in Figure 14) exhibited a fire history and subsequent establishment patterns that appear similar to those of the two stand initiation patches, where a single cohort establishes following a high 
severity event. It is possible that these results did not capture the variability in age structure within the patch, that there are trees part of a second cohort that were not sampled, or that the structure classes derived from aerial photo interpretation were not accurate. The fire event in the aforementioned understory reinitiation patch occurred 45 years before the aerial imagery was taken (and 25 years prior to the event in the stand initiation patches), which could be enough time for a second cohort to establish. Alternatively, the classifications made from the aerial photographs may not, in some cases, accurately predict stand dynamics across time. The resolution of the age structure data, as well as the delayed nature of tree recruitment makes teasing out these nuances difficult. In regards to differences in fire history within patches, the scarcity of physically sound fire scar samples, also makes the inference of very fine-scale (i.e. within patch) interpretations difficult. Regardless, there was general consistency in establishment patterns within individual patches as recorded in age structure plots, supporting the patch delineations in the two subwatersheds. 


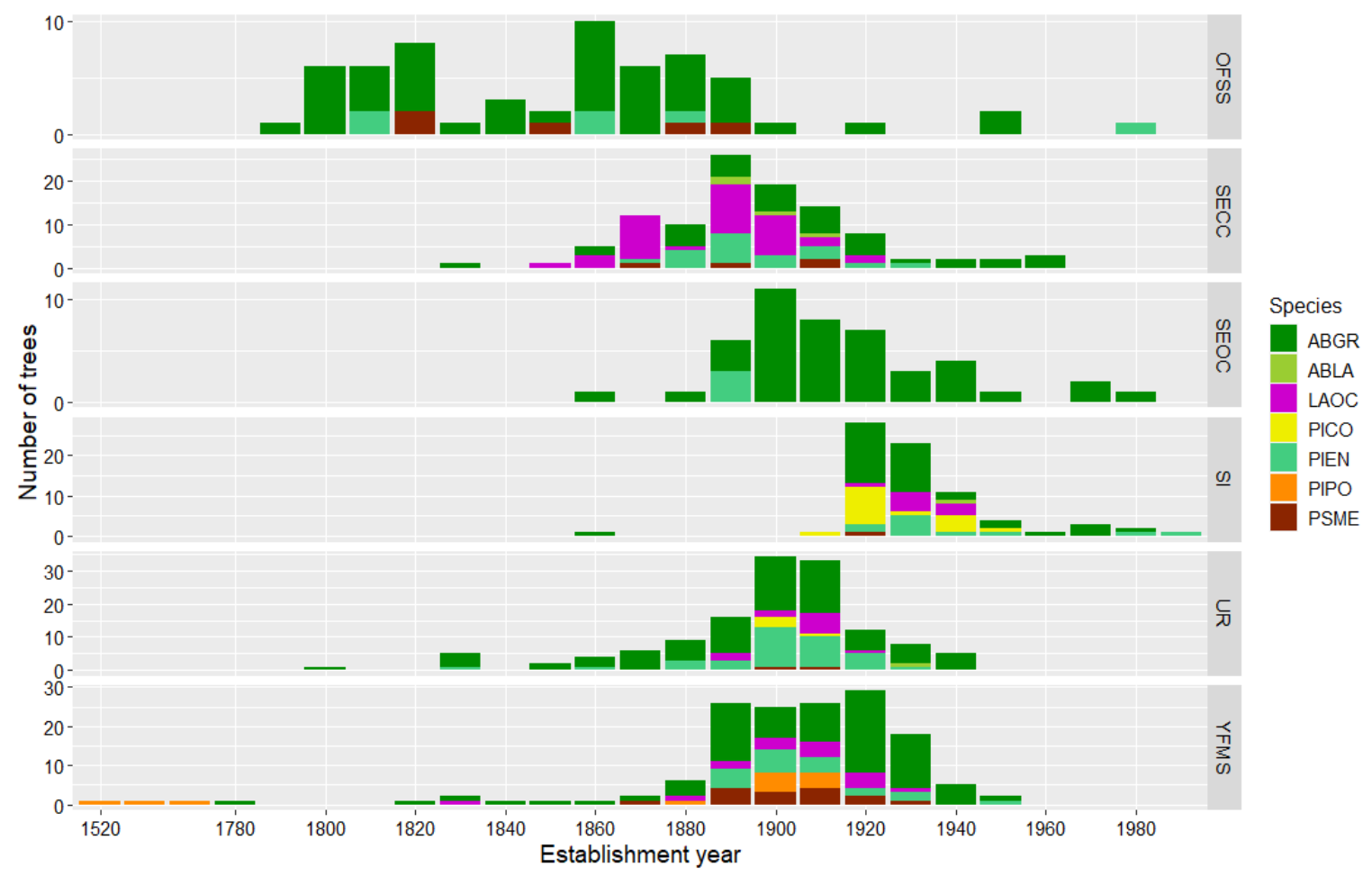

Figure 15. Establishment demography in patches grouped by forest structure type. Establishment dates are binned by decade. Species and structural class abbreviations are as follows: Grand fir (ABGR), subalpine fir (ABLA), western larch (LAOC), lodgepole pine (PICO), Engelmann spruce (PIEN), ponderosa pine (PIPO), and Douglas-fir (PSME); old forest single story (OFSS), stem exclusion closed canopy (SECC), stem exclusion open canopy (SEOC), stand initiation (SI), understory reinitiation (UR), and young forest multistory (YFMS).

\section{Study limitations}

The disturbance history of these subwatersheds was difficult to reconstruct due to the lack of intact fire scar samples. We acknowledge that limited fire scar sample depth and the corresponding small number of fire intervals may have influenced the fire interval calculations. However, relatively frequent fire confidently reconstructed via fire scars in some sites suggests that these interpretations are likely reasonable for the study area. Additionally, it is 
likely that we underestimated the number of fires experienced by these forest patches as not all fire events are recorded on even the best fire-recorder tree species (Swetnam and Baisan 1996).

A key assumption made in this study is that the cohorts identified by CharAnalysis were indeed a result of fire and not, for example, climate variability. We believe this assumption is reasonable based on a similar implementation of this approach by Tepley and Veblen (2015), where the peak detection is calibrated with a subset of the data with a confident fire record and visually apparent recruitment pulses. Additionally, a graphical comparison of a reconstructed drought index with establishment pulses did not reveal an obvious correlation between wet/dry decades and establishment peaks (Figure 10). By integrating multiple lines of evidence (e.g. pith dates, fire scar proximity, etc.) we feel that inaccurate fire attribution to patches was minimized.

\section{Future work and implications}

There is ongoing work to further refine the interpretations of historical fire regime characteristics in these, and additional subwatersheds in the BME. Another subwatershed that was sampled this past (2019) summer with the same approach will bring another 435 -tree core and 76 fire scar samples to the dataset. Additional and more comprehensive analyses, including the new samples, will likely include superposed epoch analysis to further investigate the climate-fire and climate-establishment relationships in the study area. These data will become part of a regional synthesis of patch-level fire history, structure, and 
composition to calibrate a fire severity model (see Hessburg et al. 2007) to infer whether or not current wildfires are creating forest conditions consistent with those created historically. This and future work will help establish reference conditions, and may inform management decisions in these forests. 


\section{Conclusion}

High variability in fire severity and establishment patterns across patches

illustrates the complexity of the historical forest dynamics in the study area.

Although lacking a large dataset, relatively frequent fire across the sampled subwatersheds encourages us to question the assumptions about the historical fire regime in these $\mathrm{MMC}$ forests. These findings also encourage us to appreciate variability along the fire regime spectrum, and the corresponding complexities in post-fire establishment and succession. This study highlights the challenges of reconstructing fire history in both these forest and fire regime types, and the importance of further research addressing fire history and forest change in this region. 


\section{References}

Abatzoglou, J. T., and A. P. Williams. 2016. Impact of anthropogenic climate change on wildfire across western US forests. Proceedings of the National Academy of Sciences, 113 (42):11770-11775.

Abrahamson, Ilana. Fire Effects Information System (FEIS). Available online at https://www.feis-crs.org/feis/.

Agee, J. K. 1993. Fire ecology of Pacific Northwest forests. Washington, DC: Island Press.

Agee, J. K. 1996. Fire in the Blue Mountains: a history, ecology, and research agenda. In: Search for a solution: sustaining the land, people, and economy of the Blue Mountains, ed. G. J. Raymond and T. M. Quigley, 119-145. Washington, DC: American Forests.

Andrus, R. A., B. J. Harvey, K. C. Rodman, S. J. Hart, and T. T. Veblen. 2018. Moisture availability limits subalpine tree establishment. Ecology, 99(3):567-575.

Bailey, R.G., 2009. Ecosystem geography: from ecoregions to sites 2 nd ed. Springer, New York, pp. 251.

Bowman, David M. J. S., Jennifer K. Balch, Paulo Artaxo, William J. Bond, Jean M. Carlson, Mark A. Cochrane, Carla M. D’Antonio, et al. 2009. Fire in the Earth System. Science, 324, no. 5926; 481-84.

Boyd, R. 1999. Indians, fire, and the land in the Pacific Northwest. Corvallis, OR: Oregon State University Press. 
Brewer, P.W., Velásquez, M.E., Sutherland, E.K. and Falk, D.A. .2016. Fire History Analysis and Exploration System (FHAES) version 2.0.2, [computer software], http://www.fhaes.org. DOI:10.5281/zenodo.34142

Brown, R. T., J. K. Agee, and J. F. Franklin. 2004. Forest Restoration and Fire: Principles in the Context of Place. Conservation Biology, 18 (4):903-912. Busby, S. 2019. Forest Structure, Composition, and Regeneration after HighSeverity and Rapidly Repeated Wildfires in the Central Cascade Range. M.S. Thesis. https://archives.pdx.edu/ds/psu/29605 (last accessed 8 April 2020). Cybis Elektronik. 2010. CDendro and CooRecorder.

\section{http://www.cybis.se/forfun/dendro/index.htm.}

Cobb, D. F., K. L. O'hara, and C. D. Oliver. 1993. Effects of variations in stand structure on development of mixed-species stands in eastern Washington. Canadian Journal of Forest Research, 23 (3):545-552.

Cook, E.R., D.M. Meko, D.W. Stahle, and M.K. Cleaveland. 2008. North American Summer PDSI Reconstructions, Version 2a. IGBP PAGES/World Data Center for Paleoclimatology Data Contribution Series \# 2008-046.

Davis, K. T., P. E. Higuera, and A. Sala. 2018. Anticipating fire-mediated impacts of climate change using a demographic framework ed. C. Fox. Functional Ecology, 32 (7):1729-1745. 
Duncan, R. P. 1989. An evaluation of errors in tree age estimates based on increment cores in Kahikatea (Dacrycarpus dacrydioides). New Zealand Natural Sciences, 16:31-37.

Egler, Frank E. 1954. Vegetation Science Concepts: I. Initial Floristic Composition, a Factor in Old-Field Vegetation Development. Vegetation, 4: 412-17.

Eidenshink, J., B. Schwind, K. Brewer, Z.-L. Zhu, B. Quayle, and S. Howard. 2007. A Project for Monitoring Trends in Burn Severity. Fire Ecology, 3(1): 3-21.

Fulé, P. Z., J. E. Crouse, T. A. Heinlein, M. M. Moore, W. W. Covington, and G. Verkamp. 2003. Mixed-Severity Fire Regime in a High-Elevation Forest of Grand Canyon, Arizona, USA. Landscape Ecology, 18(5): 465-85.

Gavin, Daniel G., Linda B. Brubaker, and Kenneth P. Lertzman. 2003. Holocene Fire History of a Coastal Temperate Rain Forest Based on Soil Charcoal Radiocarbon Dates. Ecology, 84(1): 186-201.

Halofsky, Joshua S., Daniel C. Donato, Jerry F. Franklin, Jessica E. Halofsky, David L. Peterson, and Brian J. Harvey. 2018. The Nature of the Beast: Examining Climate Adaptation Options in Forests with Stand-Replacing Fire Regimes. Ecosphere, 9(3): e02140.

Hanson, C. T., R. L. Sherriff, R. L. Hutto, D. A. DellaSala, T. T. Veblen, and W. L. Baker. 2015. Chapter 1 - Setting the Stage for Mixed- and High-Severity Fire. In: The Ecological Importance of Mixed-Severity Fires, edited by D. A. DellaSala and C. T. Hanson, 3-22. Elsevier. 
Hessburg, P.F., Smith, B.G., Salter, R.B. 1999. Detecting change in forest spatial patterns from reference conditions. Ecological Applications, 9:1232-1252. Hessburg, P. F., B. G. Smith, R. B. Salter, R. D. Ottmar, and E. Alvarado. 2000. Recent changes (1930s-1990s) in spatial patterns of interior northwest forests, USA. Forest Ecology and Management, 136 (1-3):53-83.

Hessburg, P. F., and J. K. Agee. 2003. An environmental narrative of Inland Northwest United States forests, 1800-2000. Forest Ecology and Management, 78: 23-59. doi: 10.1016/S0378-1127(03)00052-5. Hessburg, P.F., Agee, J.K., Franklin, J.F. 2005. Dry forests and wildland fires of the inland Northwest USA: contrasting the landscape ecology of the presettlement and modern eras. Forest Ecology and Management, 211: 117139.

Hessburg, P.F., Salter, R.B., James, K.M. 2007. Re-examining fire severity relations in pre-management era mixed-conifer forests: inferences from landscape patterns of forest structure. Landscape Ecology, 22:5-24.

Hessburg, P. F., T. A. Spies, D. A. Perry, C. N. Skinner, A. H. Taylor, P. M. Brown, S. L. Stephens, et al. 2016. Tamm Review: Management of MixedSeverity Fire Regime Forests in Oregon, Washington, and Northern California. Forest Ecology and Management, 366: 221-50.

Hessburg, P.F., Miller, C.L., Parks, S.A., Povak, N.A., Taylor, A.H., Higuera, P.E., Prichard, S.J., North, M.P., Collins, B.M., Hurteau, M.D., Larson, A.J., Allen,C.D., and Stephens, S.L. 2019. Climate, environment, and 
disturbance history govern resilience of western North American forests. Frontiers in Ecology and Evolution, 7, 1-27.

Heyerdahl, E.K., L.B. Brubaker, and J.K. Agee. 2001. Spatial controls of historical fire regimes: A multiscale example from the Interior West, USA. Ecology, 82(3), 660-678.

Heyerdahl, E. K., K. Lertzman, and C. M. Wong. 2012. Mixed-severity fire regimes in dry forests of southern interior British Columbia, Canada. Canadian Journal of Forest Research, 42, 88-98.

Heyerdahl, E. K., Loehman, R. A., \& Falk, D. A. 2019. A multi-century history of fire regimes along a transect of mixed-conifer forests in central Oregon, U.S.A. Canadian Journal of Forest Research, 49, 76-86.

Higuera, P. E. 2009. CharAnalysis 0.9: diagnostic and analytical tools for sediment-charcoal analysis. http://CharAnalysis.googlepages.com Howard, Janet L.; Aleksoff, Keith C. 2000. Abies grandis. In: Fire Effects Information System. U.S. Department of Agriculture, Forest Service, Rocky Mountain Research Station, Fire Sciences Laboratory (Producer). Available online:

https://www.fs.fed.us/database/feis/plants/tree/abigra/all.html [2020, April 8].

Johnson, E. A., K. Miyanishi, and S. R. J. Bridge. 2001. Wildfire Regime in the Boreal Forest and the Idea of Suppression and Fuel Buildup. Conservation Biology, 15(6):1554-1557. 
Johnston, J. D., Bailey, J. D., \& Dunn, C. J. 2016. Influence of fire disturbance and biophysical heterogeneity on pre-settlement ponderosa pine and mixed conifer forests. Ecosphere, 7(11).

Johnston, J. D. 2017. Forest succession along a productivity gradient following fire exclusion. Forest Ecology and Management, 392, 45-57.

Kemp, K. B., P. E. Higuera, and P. Morgan. 2016. Fire legacies impact conifer regeneration across environmental gradients in the U.S. northern Rockies. Landscape Ecology, 31 (3):619-636.

Kent, L.Y. 2014. An Evaluation of Fire Regime Reconstruction Methods. ERI Working Paper No. 32. Ecological Restoration Institute and Southwest Fire Science Consortium, Northern Arizona University: Flagstaff, AZ. 15 p.

Krawchuk, M. A., and M. A. Moritz. 2011. Constraints on global fire activity vary across a resource gradient. Ecology, 92 (1):121-132.

Littell, J. S., D. McKenzie, D. L. Peterson, and A. L. Westerling. 2009. Climate and wildfire area burned in western U.S. ecoprovinces, 1916-2003. Ecological Applications, 19 (4):1003-1021.

Merschel, A. G., T. A. Spies, and E. K. Heyerdahl. 2014. Mixed-conifer forests of central Oregon: effects of logging and fire exclusion vary with environment. Ecological Applications, 24(7): 1670-1688.

Merschel, A. G., E. K. Heyerdahl, T. A. Spies, and R. A. Loehman. 2018. Influence of landscape structure, topography, and forest type on spatial variation in historical fire regimes, Central Oregon, USA. Landscape Ecology, 33 (7):1195-1209. 
Malevich, S. B., C. H. Guiterman, and E. Q. Margolis. 2018. burnr: Fire history analysis and graphics in R. Dendrochronologia, 49:9-15.

Mock, C. J. 1996. Climatic controls and spatial variations of precipitation in the western United States. Journal of Climate, 9: 1111-1125.

Moritz, M. A., M. E. Morais, L. A. Summerell, J. M. Carlson, and J. Doyle. 2005. Wildfires, complexity, and highly optimized tolerance. Proceedings of the National Academy of Sciences 102 (50):17912-17917.

Moritz, Max A., Marc-André Parisien, Enric Batllori, Meg A. Krawchuk, Jeff Van Dorn, David J. Ganz, and Katharine Hayhoe. "Climate Change and Disruptions to Global Fire Activity." Ecosphere 3, no. 6 (2012): art49.

Naficy, C.E., T.T. Veblen, and P.F. Hessburg. 2015. Spatially explicit quantification of heterogeneous fire effects over long time series: patterns from two forest types in the northern U.S. Rockies. Pages 168-173 in Proceedings of the large wildland fires conference; May 19-23, 2014; Missoula, MT. RMRS-P-73. Fort Collins, CO: U.S. Department of Agriculture, Forest Service, Rocky Mountain Research Station. 310 p.

Naficy, C. 2016. A cross-scale assessment of historical fire severity patterns, landscape dynamics, and methodological challenges in mixed-severity fire regimes of the northern U.S. Rockies. PhD. diss., University of Colorado.

Odion, D.C., Hanson, C.T., Arsenault, A., Baker, W.L., DellaSala, D.A., Hutto, R.L., Klenner, W., Moritz, M.A., Sherriff, R.L., Veblen, T.T., Williams, M.A. 2014. Examining historical and current mixed-severity fire regimes in 
ponderosa pine and mixed-conifer forests of western North America. PLoS One, 9(2), e87852.

O'Hara, K. L., P. A. Latham, P. Hessburg, and B. G. Smith. 1996. A structural classification for Inland Northwest forest vegetation. Western Journal of Applied Forestry, 11(3):97-102.

Oregon Conservation Strategy. 2016. Oregon Department of Fish and Wildlife, Salem, Oregon.

http://www.oregonconservationstrategy.org/ecoregion/blue-mountains/

Perry, D. A., P. F. Hessburg, C. N. Skinner, T. A. Spies, S. L. Stephens, A. H. Taylor, J. F. Franklin, B. McComb, and G. Riegel. 2011. The ecology of mixed severity fire regimes in Washington, Oregon, and Northern California. Forest Ecology and Management, 262 (5):703-717.

Powell, D. C., Johnson, C. G., Jr., Crowe, E. A., Wells, A., Swanson, D. K. 2007. Potential vegetation hierarchy for the Blue Mountains section of northeastern Oregon, southeastern Washington, and west central Idaho. Gen. Tech. Rep. PNW-GTR-709. Portland, OR: U.S. Department of Agriculture, Forest Service, Pacific Northwest Research Station. PRISM Climate Group, Oregon State University, Corvallis, OR, USA. Available from http://prism.oregonstate.edu (accessed September 12 2019).

Pyne, Stephen J.; Andrews, Patricia L.; Laven, Richard D. 1996. Introduction to wildland fire. 2nd edition. New York, NY: John Wiley and Sons, Inc. 769 p. 
Schoennagel, T., T. T. Veblen, and W. H. Romme. 2004. The Interaction of Fire, Fuels, and Climate across Rocky Mountain Forests. BioScience, 54(7):661.

Schoennagel, T., R. L. Sherriff, and T. T. Veblen. 2011. Fire History and Tree Recruitment in the Colorado Front Range Upper Montane Zone: Implications for Forest Restoration. Ecological Applications, 21(6): 221022.

Sibold, J. S., T. T. Veblen, and M. E. Gonzalez. 2006. Spatial and temporal variation in historic fire regimes in subalpine forests across the Colorado Front Range in Rocky Mountain National Park, Colorado, USA. Journal of Biogeography, 33(4):631-647.

Skinner, C. N. and A. H. Taylor. 2006. Southern Cascades Bioregion. In: Sugihara, N. G., van Wagtendonk, J. W., Fites-Kaufmann, J., Shaffer, K. E., Thode, A. E., editors. 2006. Fire in California's ecosystems. University of California Press, Berkeley. pp. 195-224.

Speer, J.H. 2010. Fundamentals of Tree-Ring Research; University of Arizona Press: Tucson, AZ, USA.

Stine, P., P. Hessburg, T. Spies, M. Kramer, C. J. Fettig, A. Hansen, J. Lehmkuhl, K. O'Hara, K.Polivka, P. Singleton, S. Charnley, A. Merschel, and R. White. 2014. The ecology and management of moist mixed-conifer forests in eastern Oregon and Washington: a synthesis of the relevant biophysical science and implications for future land management. GTRPNW-897. USDA Forest Service, Portland, Oregon. 
Stokes, M. A. and T. L. Smiley. 1968. An introduction to tree-ring dating. Chicago, IL: University of Chicago Press.

Swetnam, T. W. and C. H. Baisan. 1996. Historical Fire Regime Patterns in the Southwestern United States Since AD 1700. Pages 11-32 in Proceedings of the Second La Mesa Fire Symposium, Los Alamos, New Mexico.

Taylor, A. H. and C. N. Skinner. 1998. Fire history and landscape dynamics in a late-successional reserve, Klamath Mountains, California, USA. Forest Ecology and Management, 111:285-301.

Tepley, A. J., F. J. Swanson, and T. A. Spies. 2013. Fire-mediated pathways of stand development in Douglas-fir/western hemlock forests of the Pacific Northwest, USA. Ecology, 94 (8):1729-1743.

Tepley, A. J., F. J. Swanson, and T. A. Spies. 2014. Post-fire tree establishment and early cohort development in conifer forests of the western Cascades of Oregon, USA. Ecosphere, 5 (7):80.

Tepley, A. J., and T. T. Veblen. 2015. Spatiotemporal fire dynamics in mixedconifer and aspen forests in the San Juan Mountains of southwestern Colorado, USA. Ecological Monographs, 85 (4):583-603.

Turner, M. G. 2010. Disturbance and landscape dynamics in a changing world. Ecology, 91(10): 2833-2849.

Uchytil, Ronald J. 1991. Picea engelmannii. In: Fire Effects Information System. U.S. Department of Agriculture, Forest Service, Rocky Mountain Research Station, Fire Sciences Laboratory (Producer). Available: https://www.fs.fed.us/database/feis/plants/tree/piceng/all.html 
Villalba R. and T. T. Veblen. 1997. Improving estimates of total tree ages based on increment core samples. Ecoscience, 4(4): 534-542.

Walsh, M. K., J. R. Marlon, S. J. Goring, K. J. Brown, and D. G. Gavin. 2015. A Regional Perspective on Holocene Fire-Climate-Human Interactions in the Pacific Northwest of North America. Annals of the Association of American Geographers, 105 (6):1135-1157.

Westerling, A. L., H. G. Hidalgo, D.R. Cayan, and T. W. Swetnam. 2006. Warming and Earlier Spring Increase Western U.S. Forest Wildfire Activity. Science, 313 (5789):940-943.

Western Regional Climate Center, 2019. Climate of Oregon. [Available online at https://wrcc.dri.edu/narratives/OREGON.htm.]

Yamaguchi, D. K. 1991. A simple method for cross-dating increment cores from living trees. Canadian Journal of Forest Research, 21(3): 414. 


\section{Appendix A - Reconstructing fire history from tree ring evidence}

The purpose of this appendix is to provide a brief background in tree ring data and its relevance to fire history reconstructions, and outline the techniques used in our study to collect the tree ring samples and fire history data therein.

The science of tree ring dating, or dendrochronology, is a widely used approach to reconstruct fire history in forests (Speer 2010). Many attributes of fire patterns over time in a particular area (i.e. a fire regime), can be inferred from the natural record in tree rings. These attributes often include fire interval (number of years between successive fire events), severity (loss of organic matter, e.g. proportion of trees killed following a fire event), size (area burned), and even seasonality. Trees can respond to, and therefore record, fire in different ways, and in order to reconstruct fire in a forest where the response is expected to vary widely (as in the moist mixed-conifer forests of the northern Blue Mountains), integrating multiple lines of evidence is the strongest approach to providing an accurate representation of historical fire patterns (Stine et al. 2014; Kent 2014).

In forests where frequent, low severity fires are common, fire scarred trees are often prevalent in the landscape and can serve as point data for fire occurrence (Swetnam and Baisan 1996). Low severity fires leave many surviving trees, some of which were likely injured. In an injured tree, only a portion of the cambium (a tree's thin layer of growing tissue) is killed by the fire, leaving the remaining portion to grow around the wound (Figures $1 \& 3$ ). Trees, such as ponderosa pine, that are typical inhabitants of ecosystems with these high frequency, low severity fire regimes are well accustomed to fire and have the ability to survive and recover from numerous fire events. These trees that survive multiple fires, and record that evidence in their rings, can be a reliable proxy for interpreting fire years across the landscape. Fire scars from multiple trees are compiled within a forest stand or patch, and fire years can then be compared 
within and across forest patches, across watersheds and even across regions to analyze local and widespread fire activity (Swetnam and Baisan 1996).
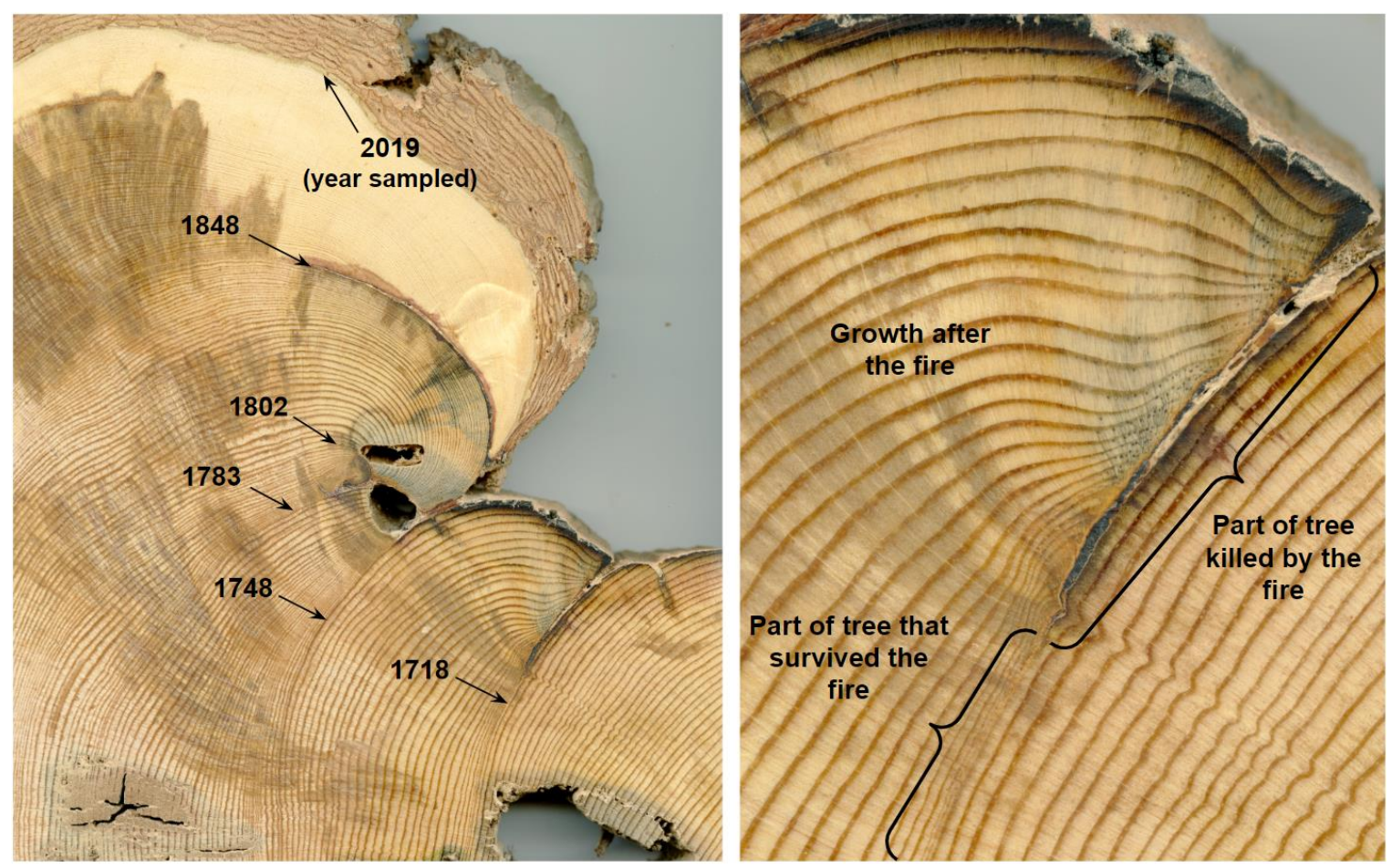

Figure 1. (Left) A partial cross-section sample cut with a chainsaw from a fire-scarred ponderosa pine (Pinus ponderosa) in the northern Blue Mountains. Dates of fire events and sampling are marked on the section. (Right) Close-up of the 1718 fire scar year in the same cross-section, illustrating the tree's growth response to a fire injury.

In forests where crown (treetop) fires occur, a relatively high proportion of overstory trees are killed in these high severity fire events (Agee 1993). Surviving fire- scarred trees, and the high-resolution fire history records within, are less common in landscapes prone to high severity fire. When a high proportion of overstory trees in a stand are killed by fire, the resulting resource availability (e.g. space and light) is conducive to tree establishment (Oliver and Larson 1990). In these forests, or forest patches, cohorts of even-aged trees can be used as evidence of the fire that preceded them (Barrett and Arno 1988). The resolution of these data, however, is not as fine as that from fire scars due to error in estimating establishment dates (e.g. missing pith) and likely extension of tree 
recruitment in the burned area for several years post-fire (Oliver and Larson 1990).

In forests that are expected to have experienced both low and high severity fires, such as in the northern Blue Mountains, a combination of fire scar data and cohort data can be used as evidence of fire. In the Jubilee Lake study area, fire scars were available, but intact and readable fire scars were quite rare. The scarred trees we found were predominantly on grand fir, the tree species most ubiquitous to our sampled sites. Since grand fir are not decay-resistant trees (Aho 1977), the fire scar records rotted away with the wood after the tree was injured. We were only able to use $2 \%$ of the grand fir fire scars collected, and $32 \%$ of the total samples collected in the fire history reconstruction (Figure 2). The majority of usable fire scars were collected on ponderosa pine trees on patch boundaries, and occasionally in forest stands downslope of sampled patches.

The technique we used to sample the partial cross-sections (Figure 3) involves removing a small portion of the tree's stem with a chainsaw (Arno and Sneck 1973). To reduce impact on living trees, we prioritized sampling dead trees when possible. However, the nature of the moist mixed-conifer forests where we were sampling meant that most dead trees quickly succumbed to rot. Many of the fire scar samples found on downed logs, stumps, and snags (dead standing trees) did not have intact fire scars. 


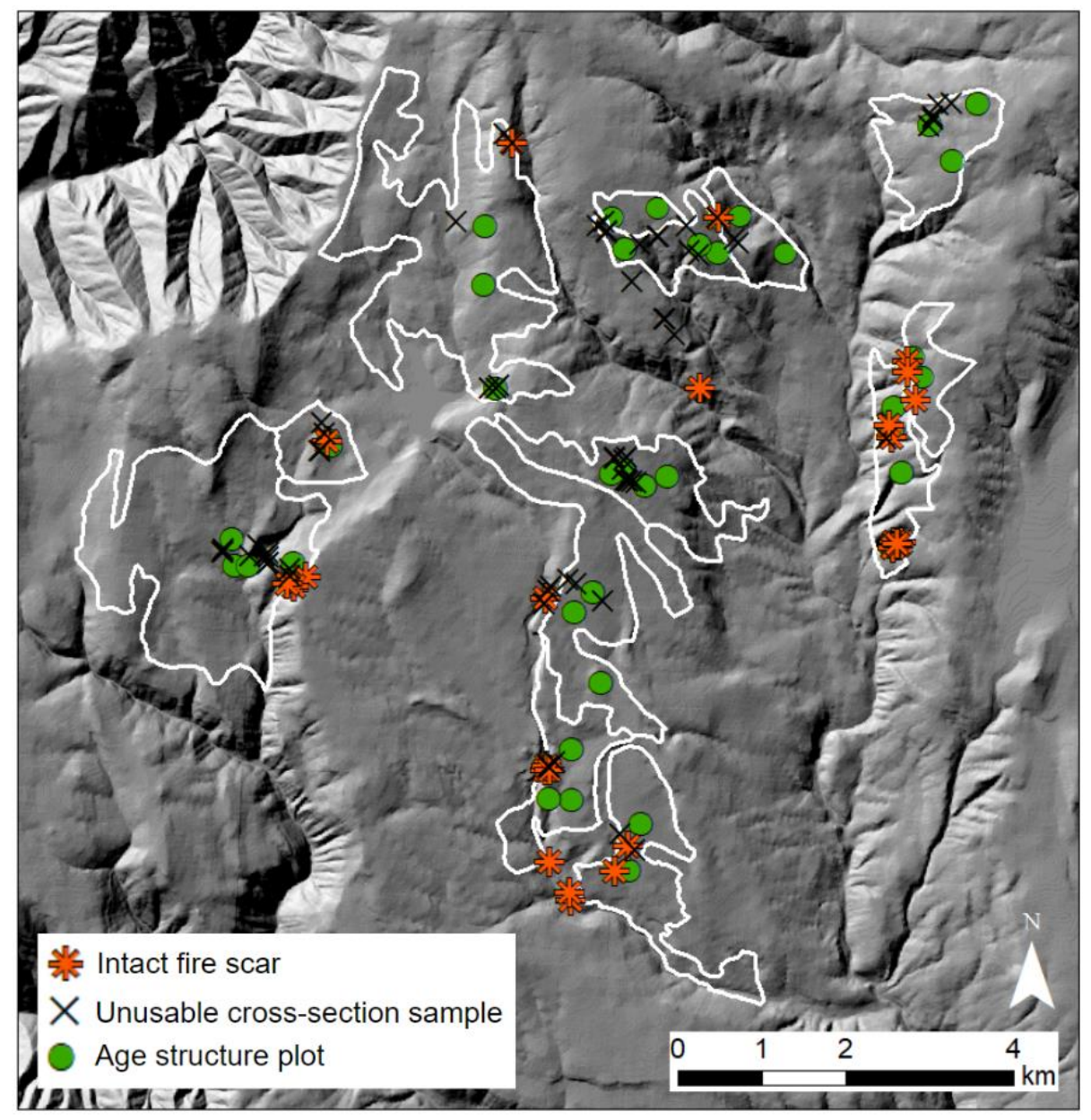

Figure 2. Spatial distribution of partial cross-sections collected in the Jubilee Lake study area.

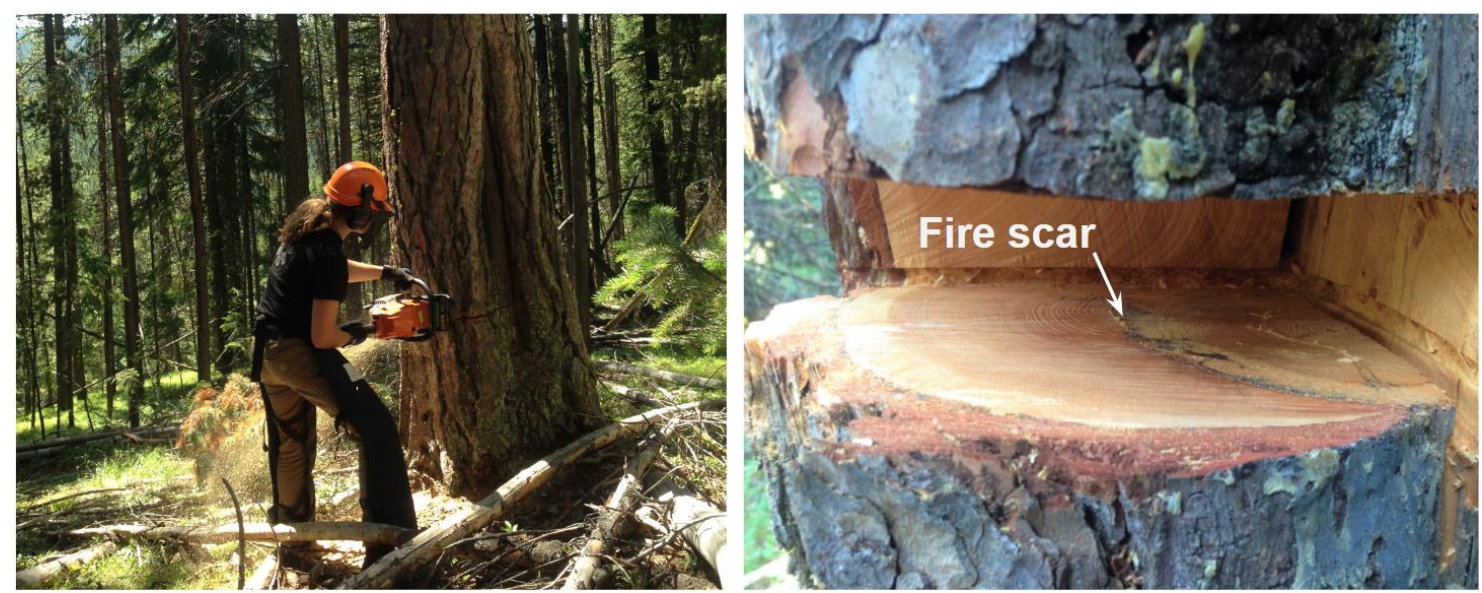

Figure 3. (Left) Collection of a partial cross-section from a fire-scarred western larch (Larix occidentalis). The section of cambium injured by a previous fire is just visible on the upslope side of the tree and is slowly being enclosed by the post-fire growth of the tree. (Right) Looking inside a sampled tree with the partial cross-section removed. A fire scar, where the living cambium met the dead cambium the year of the fire, is labeled. 


\section{References:}

Agee, J. K. 1993. Fire ecology of Pacific Northwest forests. Washington, DC: Island Press.

Aho, Paul E. 1977. Decay of grand fir in the Blue Mountains of Oregon and Washington. Res. Pap. PNW-229. Portland, OR: U.S. Department of Agriculture, Forest Service, Pacific Northwest Forest and Range Experiment Station. $18 \mathrm{p}$.

Arno, S. F., and K. M. Sneck. 1973. A method for determining fire history in coniferous forests of the mountain west. USDA Forest Service General Technical Report INT-42. 35p.

Barrett, S. F. and S. F. Arno. 1988. Increment-borer methods for determining fire history in coniferous forests. General Technical Report INT-244. Ogden, UT, USDA Forest Service, Intermountain Research Station.

Kent, L.Y. 2014. An Evaluation of Fire Regime Reconstruction Methods. ERI Working Paper No. 32. Ecological Restoration Institute and Southwest Fire Science Consortium, Northern Arizona University: Flagstaff, AZ. 15 p.

Oliver, C.D. and B. C. Larson. 1990. Forest Stand Dynamics. McGraw-Hill Book Company, New York. 467 pp

Speer, J.H. 2010. Fundamentals of Tree-Ring Research; University of Arizona Press: Tucson, AZ, USA.

Stine, P., P. Hessburg, T. Spies, M. Kramer, C. J. Fettig, A. Hansen, J. Lehmkuhl, K. O'Hara, K.Polivka, P. Singleton, S. Charnley, A. Merschel, and R. White. 2014. The ecology and management of moist mixed-conifer forests in eastern Oregon and Washington: a synthesis of the relevant biophysical science and implications for future land management. GTR-PNW-897. USDA Forest Service, Portland, Oregon.

Swetnam, T. W. and C. H. Baisan. 1996. Historical Fire Regime Patterns in the Southwestern United States Since AD 1700. Pages 11-32 in Proceedings of the Second La Mesa Fire Symposium, Los Alamos, New Mexico. 


\section{Appendix B - Estimation of fire severity}

In order to calculate event-level fire severity metrics per patch, we used a method developed by Tepley and Veblen (2015) and used in the mixed-severity fire regime forests of the San Juan Mountains in Colorado. This derivation of fire severity is based on a function $d_{\mathrm{i}}\left(n_{\mathrm{i}}\right)$, that describes the rate at which tree density $(d)$ decreases over time with each sequential fire event $(n)$ for the $i^{\text {th }}$ forest stand (i.e. patch). This function is compared to the same function averaged, $\bar{d}(n)$, across all forest patches within the study area to estimate cumulative fire severity $S\left(n_{\mathrm{i}}\right)$. The event-level severity metric, $\Delta S\left(n_{i}\right)$, is then calculated as the proportional change in the cumulative severity metric with each sequential fire added, going back in time in the fire record. Equations for calculating each of the above metrics and are listed below.

Eq.1: Average density (where $m$ represents the total number of sampled patches; $m=13$ for this study).

$$
\overline{\mathrm{d}}(\mathrm{n})=\frac{\sum_{i=1}^{m} \mathrm{~d}_{\mathrm{i}}\left(\mathrm{n}_{\mathrm{i}}\right)}{m}
$$

Eq.2: Cumulative fire severity over a given number of fires.

$$
\mathrm{S}\left(\mathrm{n}_{\mathrm{i}}\right)=\frac{\mathrm{d}_{\mathrm{i}}\left(\mathrm{n}_{\mathrm{i}}\right)}{\overline{\mathrm{d}}(\mathrm{n})}
$$

Eq.3: Relative, event-level fire severity, calculated as the proportional change to $S\left(n_{i}\right)$. The proportional change is multiplied by -1 so that increasing $\Delta S\left(n_{i}\right)$ values correspond to increasing fire severity.

$$
\Delta S\left(n_{i}\right)=-1 X \frac{S\left(n_{i}\right)-S\left(n_{i}-1\right)}{S\left(n_{i}-1\right)}
$$

Once fire severity was estimated for each fire event via the above equations, each event-level metric was placed into a low, moderate, or high severity class based on thresholds of stand basal area surviving the fire, consistent with commonly accepted and widely used values (Naficy 2016; Agee 1993). 


\section{References:}

Agee, J. K. 1993. Fire ecology of Pacific Northwest forests. Washington, DC: Island Press.

Naficy, C. 2016. A cross-scale assessment of historical fire severity patterns, landscape dynamics, and methodological challenges in mixed-severity fire regimes of the northern U.S. Rockies. PhD. diss., University of Colorado.

Tepley, A. J., and T. T. Veblen. 2015. Spatiotemporal fire dynamics in mixedconifer and aspen forests in the San Juan Mountains of southwestern Colorado, USA. Ecological Monographs, 85 (4):583-603. 